\title{
Experimental Tests and Analytical Modelling of a Scaled Isolated Structure on Sliding and Elastomeric Bearings
}

\author{
Fabio Mazza and Alfonso Vulcano \\ Dipartimento di Ingegneria Civile, Università della Calabria, Arcavacata, Rende, 87036 Cosenza, Italy \\ Correspondence should be addressed to Fabio Mazza; fabio.mazza@unical.it
}

Received 23 August 2015; Revised 8 December 2015; Accepted 13 December 2015

Academic Editor: Luca Caracoglia

Copyright ( 2016 F. Mazza and A. Vulcano. This is an open access article distributed under the Creative Commons Attribution License, which permits unrestricted use, distribution, and reproduction in any medium, provided the original work is properly cited.

\begin{abstract}
The main purpose of this study, which was conducted within the framework of a DPC-ReLUIS research project, was to investigate the behaviour of a scaled isolated structure equipped with an in-parallel combination of steel-PTFE sliding bearings and elastomeric bearings (HDRBs). For this purpose, dynamic tests on shaking table were carried out at the Laboratory of the Department of Structures for Engineering and Architecture of the University of Naples Federico II, Italy. An available prototype steel framed structure was used as a superstructure. A further objective of this study was to evaluate the reliability of different analytical models of the isolation system, commonly used, in order to adequately simulate the dynamic response of the isolated structure. The effectiveness of the isolation system was evaluated comparing the experimental response of the isolated structure with the numerical response of the fixed-base structure.
\end{abstract}

\section{Introduction}

Base-isolation of a structure subjected to an earthquake allows a considerable reduction of the horizontal loads transmitted to the superstructure (Naeim and Kelly [1]). The following isolation strategies, or a suitable combination of them, can be used (Braga et al. [2]): increase of the fundamental vibration period of the structure (e.g., using elastomeric bearings), to shift it in the range of low spectral accelerations; limitation of the maximum force transmitted to the superstructure (e.g., using steel-PTFE sliding bearings with plane/curved surface or damping devices). Different isolation systems were studied by many authors (e.g., Dolce et al. [3]; Ponzo et al. [4]; Sorace et al. [5]). The nonlinear dynamic response of different base-isolated framed structures was studied in previous works (Mazza and Vulcano [6, 7]; Mazza et al. [8]).

This study was conducted within the framework of Task 2.3.2 of DPC-ReLUIS 2010-2013 research project aiming to experimentally validate the effectiveness of different isolation systems for a building structure. For this purpose, different scaled isolated structures were designed for an available prototype steel framed structure, assumed to be the superstructure. A wide experimental campaign was conducted for scaled isolated structures subjected to dynamic tests on shaking table at the Laboratory of the Department of Structures for Engineering and Architecture of the University of Naples Federico II, Italy. More precisely, the main purpose of this study was to investigate the behaviour and effectiveness of base-isolated structures in case an in-parallel combination of elastomeric bearings (HDRBs) and plane steel-PTFE sliding bearings is used. The reliability of different analytical models of the isolation system which are commonly used in simulating the dynamical response was evaluated comparing experimental and numerical results. The effectiveness of the isolation system was also evaluated, comparing the experimental response of the isolated structure with the numerical response of the fixed-base structure.

\section{Description of Superstructure and Bearings}

The 1/3 scaled steel frame model shown in Figure 1 was considered to be the superstructure. Its main properties are summarized below: 


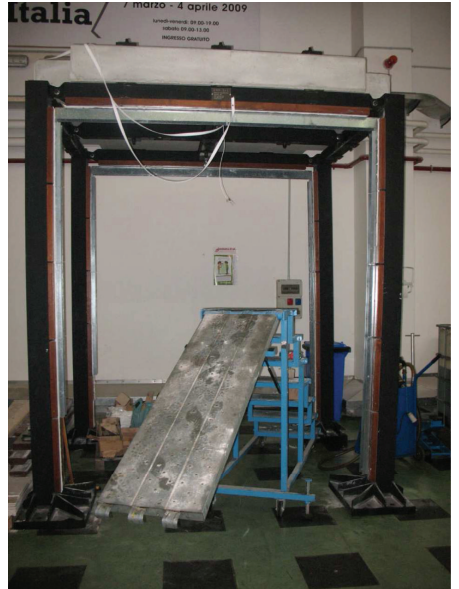

FIGURE 1: Superstructure of the experimental campaign.

(i) Plan dimensions are $2650 \mathrm{~mm} \times 2150 \mathrm{~mm}$, with a total height of about $2900 \mathrm{~mm}$.

(ii) The columns have welded square hollow sections $(150 \mathrm{~mm} \times 150 \mathrm{~mm} \times 15 \mathrm{~mm})$.

(iii) Beams have rolled square hollow sections $(120 \mathrm{~mm} \times$ $120 \mathrm{~mm} \times 12.5 \mathrm{~mm}$ ).

(iv) Pin connections were used between beams and columns.

(v) The roof of the structure, supporting a reinforced concrete slab, had a mass of 4.1 tons, and the total mass of the superstructure was 5.35 tons.

(vi) The fundamental period of the fixed-base structural model was about $0.26 \mathrm{~s}$ (Magliulo et al. [9]), which, considering the scale factor, corresponds to $0.45 \mathrm{~s}$ (this may be intended to be the fundamental period expected for a four-storey steel framed structure).

(vii) The damping ratio was about $0.65 \%$, according to free vibration decay method [9].

Four steel-PTFE sliding bearings and two elastomeric isolators (HDRBs), all with circular cross section, were manufactured and provided by FIP Industriale S.p.A. (Padova, Italy). The main geometric and manufacturing characteristics of the bearings are illustrated in Figure 2 and Tables 1 and 2 .

A small size of a sliding bearing (diameter of the PTFEslider $\phi=60 \mathrm{~mm}$ ) was chosen to have a pressure sufficiently high (about $7.5 \mathrm{~N} / \mathrm{mm}^{2}$ ) to avoid reaching a very high value of the friction coefficient. Because the motion for the tests was foreseen in one direction, two elastomeric bearings only were considered to limit their cost.

On the basis of many tests performed by the manufacturer on similar devices, a friction coefficient of $6 \%$ was assumed for a PTFE-slider. Moreover, each elastomeric bearing was produced to have a (secant) horizontal stiffness $K_{\mathrm{si}}=$ $0.22 \mathrm{kN} / \mathrm{mm}$ at a displacement of $\pm 130 \mathrm{~mm}$, corresponding to a shear strain of $100 \%$ and equivalent viscous damping of about $15 \%$. The above displacement was assumed to be that corresponding to the collapse of the elastomeric bearing.
TABLE 1: Components of a steel-PTFE sliding bearing.

\begin{tabular}{lc}
\hline Components & Materials \\
\hline Screws TE M10 × 30 & Class 8.8 EN 20898 \\
Washer for M10 & \\
Hard screw M5 $\times 14$ & A4/80 \\
Plain slider $330 \times 330 \times 2.5$ & AISI 316L EN-10088 \\
Plate $340 \times 340 \times 13$ & S355JR \\
Slider $\phi 59.8 \times 5$ & PTFE (with niches) \\
Cylinder $\phi 70 \times 60$ & S355JR \\
\hline
\end{tabular}

TABLE 2: Components of an elastomeric bearing (HDRB).

\begin{tabular}{lcc}
\hline Position & Components & Materials \\
\hline 7 & Screws TE M10 $\times 30$ & Class 8.8 EN 20898 \\
6 & Connecting plate (upper) & S275JR EN 10025 \\
5 & Connecting plate (lower) & S275JR EN 10025 \\
4 & Vulcanized rubber & Gdin $=0.4$ N $/ \mathrm{mm}^{2}$ \\
3 & Strengthening vulcanized sheet & S275JR EN 10025 \\
2 & Vulcanized plate & S275JR EN 10025 \\
1 & Connecting screw TE M16 & Class 8.8 EN 20898 \\
\hline
\end{tabular}

\section{Characterization Tests of the Isolation System}

3.1. Experimental Set-Up and Instrumentation. To isolate the superstructure described above, the four sliding bearings, previously lubricated, were placed under the corners of the (horizontal) frame at the base of the superstructure, with the vertical axis correspondent to the axis of a column (Figures 3(a) and 3(b)). Each of the two elastomeric bearings was placed on the external side corresponding to the middle of a girder of the base frame having the axis parallel to the direction of motion imposed to the shaking table for the tests (Figure 3(c)). Main details of the connection of the bearings to the shaking table and a vertical view of the bearings are shown in Figure 4. An added mass, made up of concrete blocks having a total weight of $33.2 \mathrm{kN}$, was placed and connected to the horizontal frame at the base of the superstructure. All the weights and corresponding masses are reported in Table 3. Plan views of the added mass at the base and concrete slab at the top of the superstructure are represented in Figures 5(a) and 5(b), respectively.

The isolated steel frame model aimed to simulate a $1 / 3$ scaled isolated structure. An approximated value of the fundamental period of the isolated structure model was obtained idealizing the isolated structure as a single-degreeof-freedom (SDOF) system. The total mass being equal to $8.56 \mathrm{kNs}^{2} / \mathrm{m}$ (see Table 3 ) and the (secant) stiffness of the isolation system practically being equal to the total secant stiffness of the two elastomeric bearings, that is, $0.44 \mathrm{kN} / \mathrm{mm}$ (neglecting the contribution of the sliding bearings), the period of the scaled isolated structure was evaluated as about $0.87 \mathrm{~s}$. Considering the scale factor, this corresponds to a period of an isolated structure of about $1.51 \mathrm{~s}$ that is 3.35 times the period of the fixed-base structure $(0.45 \mathrm{~s})$. 


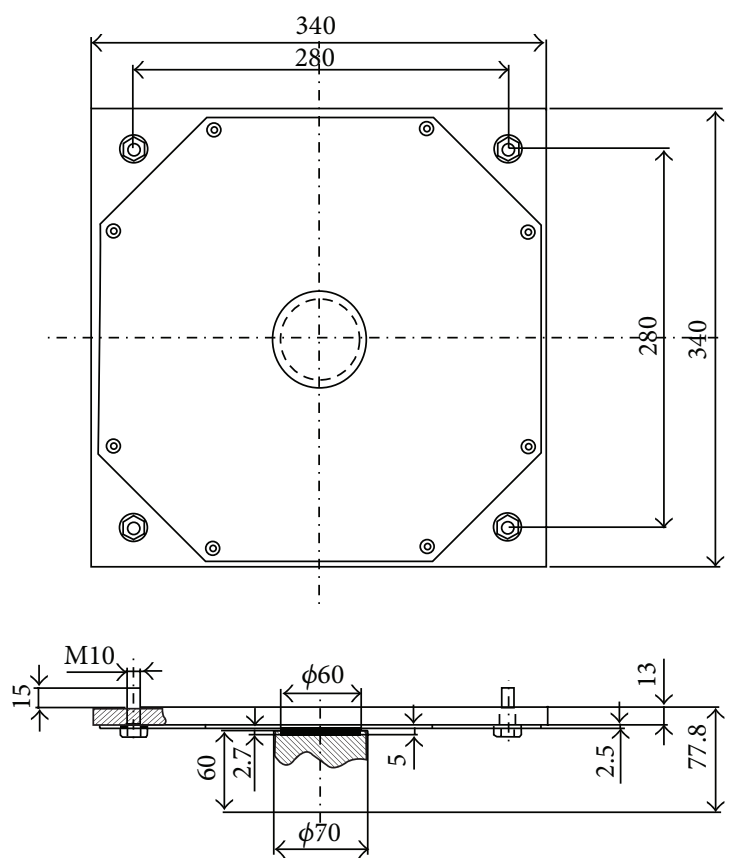

(a) PTFE sliding bearing

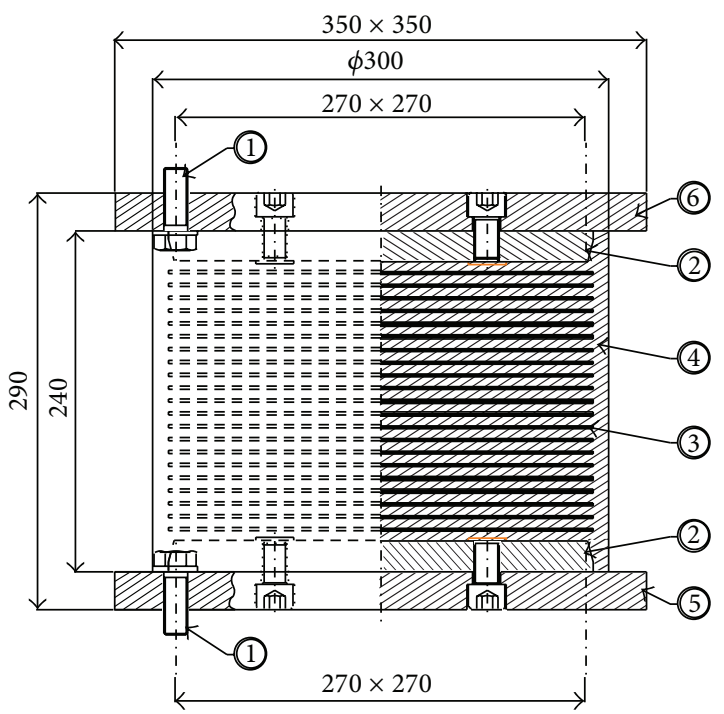

(b) Elastomeric bearing (HDRB)

FIGURE 2: Geometric characteristics of the bearings.

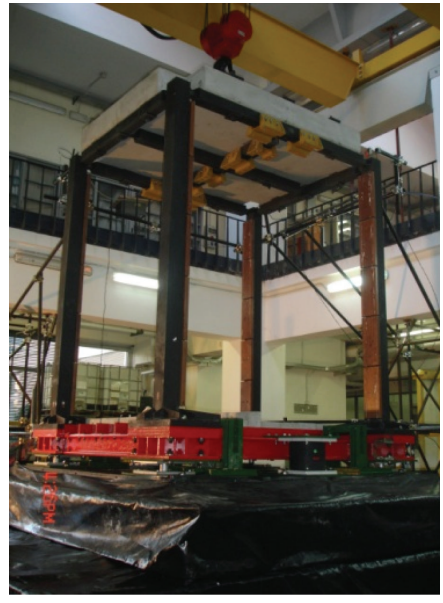

(a) General view
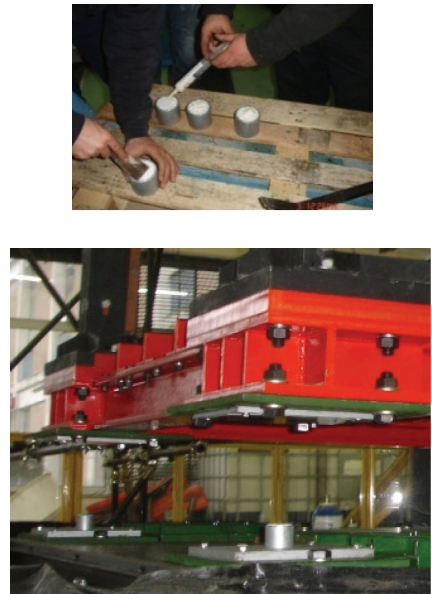

(b) Sliding bearings and their arrangement
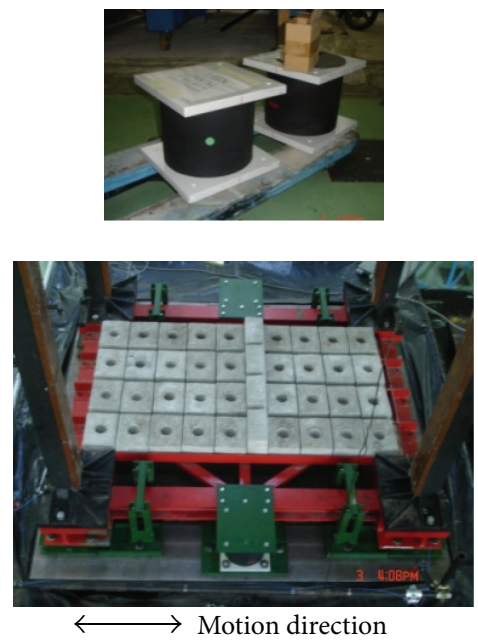

(c) Elastomeric bearings and their arrangement

Figure 3: Views of the scaled isolated structure.

Many kinds of transducers, as specified in Table 4, were used and arranged in plan as shown in Figure 5 on the shaking table platform and base frame and at the top of superstructure. In particular, the laser-displacement sensors, connected to an external reference steel frame, measured the absolute displacements in the direction of the applied motions, while the triaxial accelerometers measured the acceleration components.
3.2. Dynamic Tests. To characterize the isolation system, different shaking table tests of the isolated structure were carried out studying the free vibrations following a steadystate harmonic motion of the table. Frequency and peak acceleration of the shaking table during the tests are reported in Table 5. Acceleration and displacement measured during test 4 are shown in Figure 6. The corresponding relative displacements of the isolated system and superstructure, 

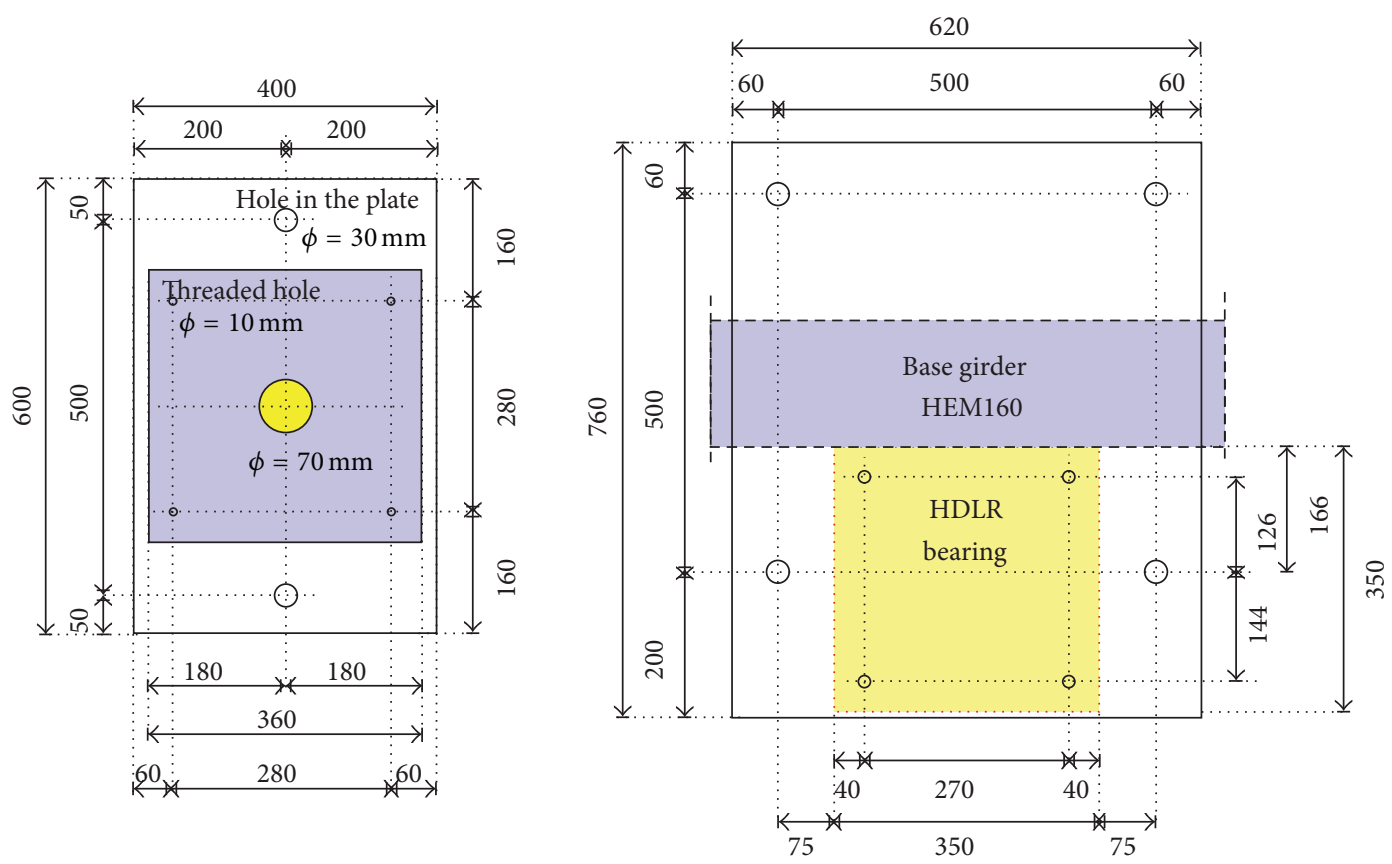

(a) Plan of connecting plates to the shaking table (dimensions in $\mathrm{mm}$ )

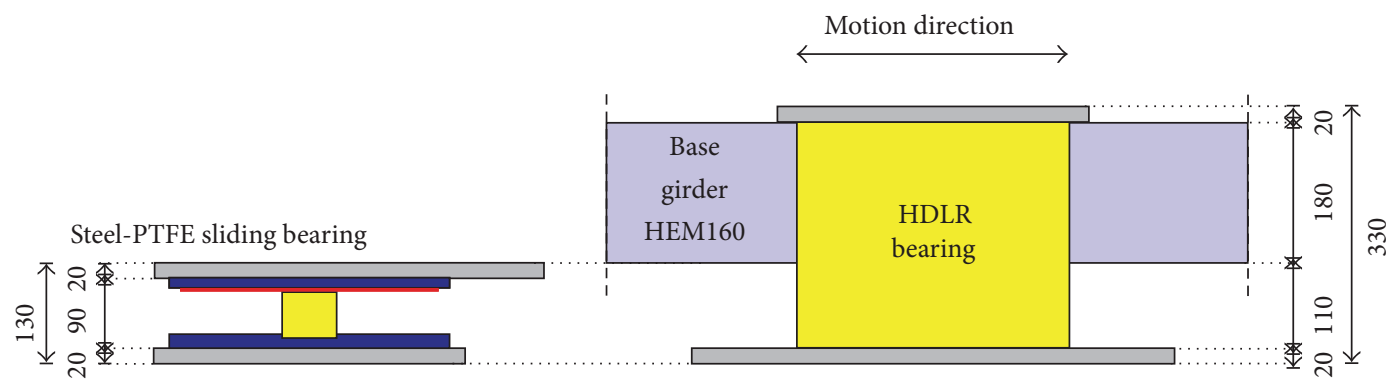

(b) Vertical view

FIgURE 4: Connection of the sliding and elastomeric bearings (dimensions in $\mathrm{mm}$ ).

TABLE 3: Weights and masses.

\begin{tabular}{lcc}
\hline Components & $\begin{array}{c}\text { Weight } \\
(\mathrm{kN})\end{array}$ & $\begin{array}{c}\text { Mass } \\
\left(\mathrm{kN} \mathrm{s}^{2} / \mathrm{m}\right)\end{array}$ \\
\hline Columns & 7.26 & 0.74 \\
Perimeter girders & 4.66 & 0.48 \\
Base plates & 4.51 & 0.46 \\
Plates and bolts & 3.83 & 0.39 \\
Concrete slab (top) & 33.20 & 3.39 \\
Horizontal base frame & 19.00 & 1.94 \\
Concrete blocks (on base frame) & 9.52 & 0.97 \\
Connecting plates (elastomeric isolators) & 1.17 & 0.12 \\
Connecting plates (sliding isolators) & 0.52 & 0.06 \\
Bolts (connecting plates) & 0.2 & 0.02 \\
\hline Total & $\mathbf{8 3 . 8}$ & $\mathbf{8 . 5 6}$ \\
\hline
\end{tabular}

measured on both sides of the base frame (see location of sensors W4 and W6 in Figure 5(a)), proved a practical symmetry of the motion (Figure 7).

It should be noted that it has been considered more realistic to simulate the dynamic response of the entire isolated structural system (instead of considering the response of the single device), because of the uncertainties in the connections between the single parts constituting the isolation system.

3.3. Characterization by Viscoelastic Model. On the basis of the above shaking table tests, it was possible to characterize the isolation system. For this purpose, the isolated structure was idealized as the two-degree-of-freedom (2-DOF) system shown in Figure 8, where: $m_{0}$ and $m_{1}$ represent the masses supposed to be lumped at the top and base floor levels of the superstructure, respectively; $2 \times k_{0}(=2 \times 1429.6=$ $2859.2 \mathrm{kN} / \mathrm{m}$ ) was the elastic (lateral) stiffness of the steel superstructure, while $k_{I}$ represented the equivalent stiffness of the isolation system. 


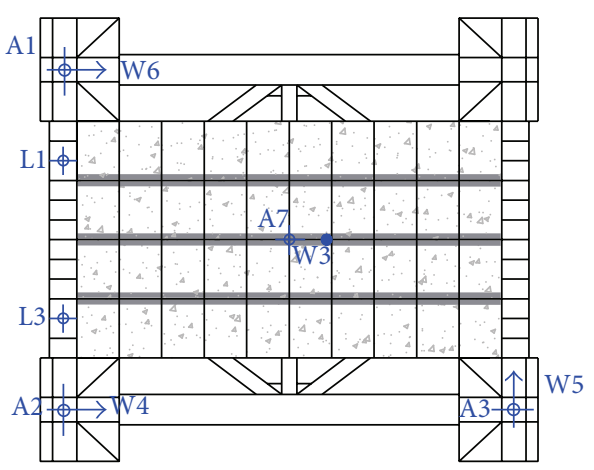

(a) On shaking table platform and base frame

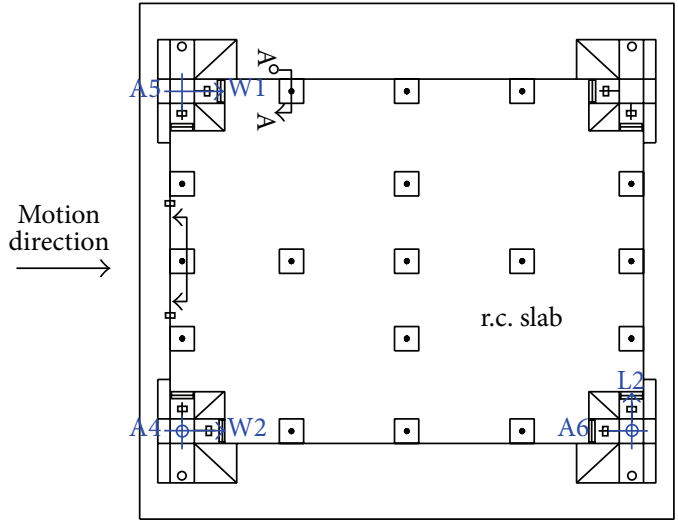

(b) At the top of the superstructure

FIGURE 5: Location of transducers.

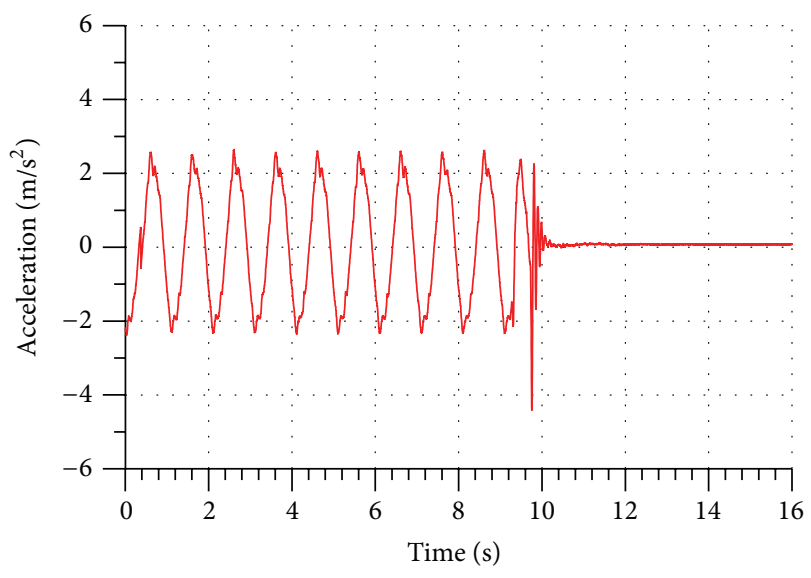

(a) Acceleration

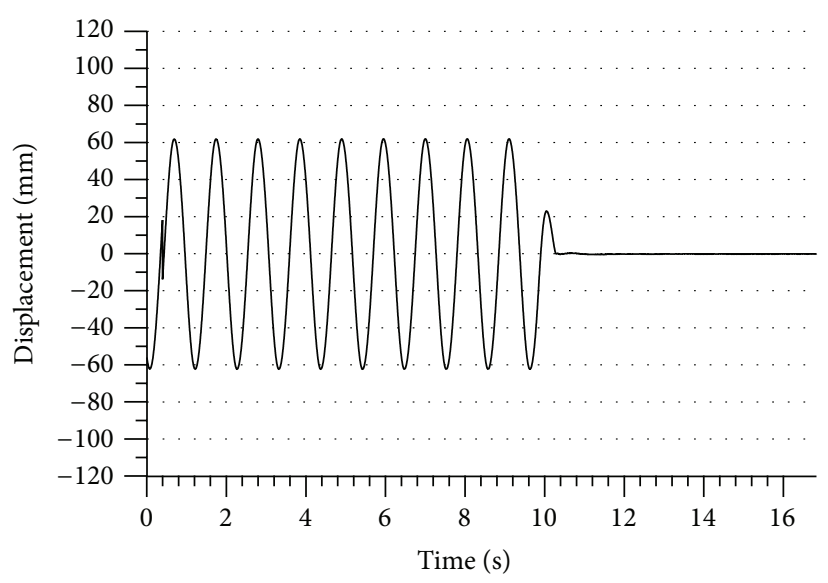

(b) Displacement

FIgURE 6: A shaking table motion for characterization of the isolation system (test 4).

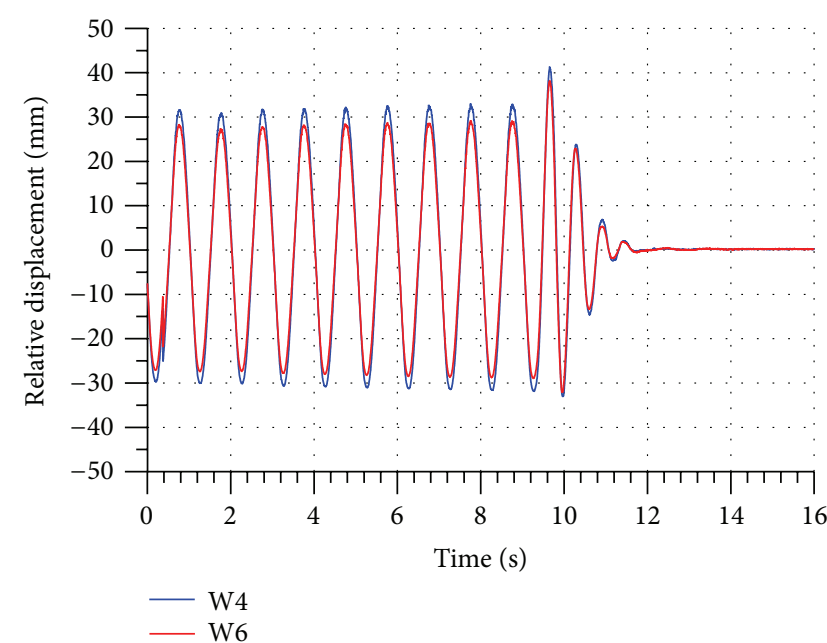

(a) Isolation system

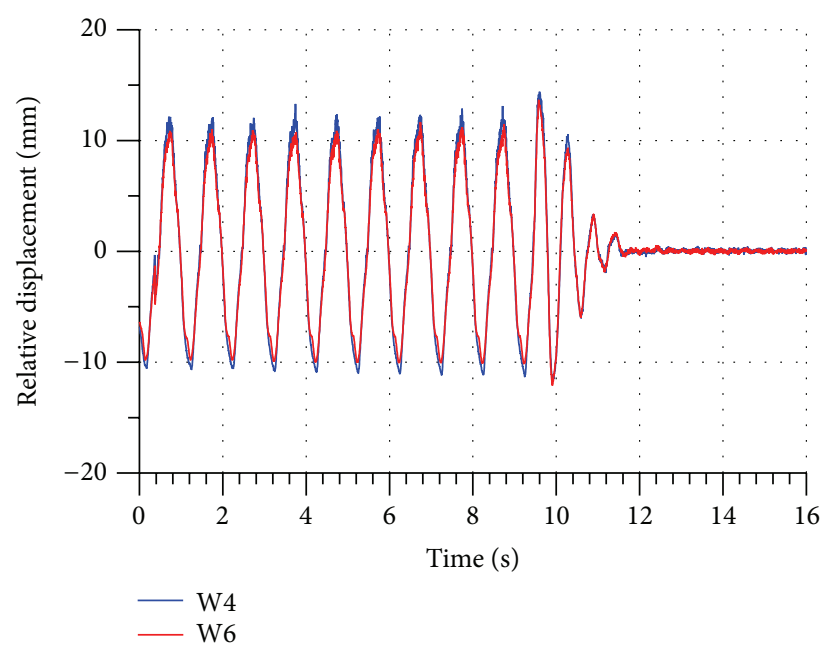

(b) Superstructure

FIGURE 7: Steady-state forced and free vibrations (test 4; W4 and W6 transducers; see Figure 5(a) and Table 4). 
TABLE 4: Transducers ( $X, Y$ horizontal directions; $Z$ vertical direction).

\begin{tabular}{llcc}
\hline Label & Measure description & Direction & Kind \\
\hline A7 & Acceleration of the shaking table & $X, Y, Z$ & PCB triaxial accelerometer \\
A1, A2, and A3 & Acceleration of the superstructure base & $X, Y, Z$ & PCB triaxial accelerometer \\
A4, A5, and A6 & Acceleration of the superstructure top & $X, Y, Z$ & PCB triaxial accelerometer \\
W3 & Displacement of the shaking table & $Y$ (motion direction) & Wenglor laser transducer \\
W4, W6 & Displacement of the superstructure base & $Y$ & Wenglor laser transducer \\
W5 & Displacement of the superstructure base & $X$ & Wenglor laser transducer \\
L1, L3 & Displacement of the superstructure base & $Z$ & Micro-Epsilon laser transducer \\
W1, W2 & Displacement of the superstructure top & $Y$ & Wenglor laser transducer \\
L2 & Displacement of the superstructure top & $X$ & Micro-Epsilon laser transducer \\
\hline
\end{tabular}

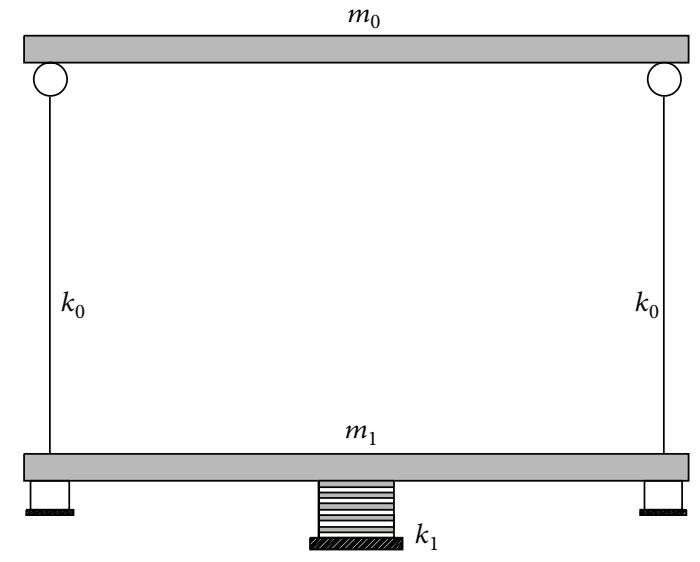

FIGURE 8: Idealization of the isolated structure by a two-degree-offreedom system.

With reference to the free vibrations following the steadystate forced phase, it was possible to identify (Table 6):

(i) period of the isolated structure (experimentally);

(ii) damping factor $(\xi)$, as average of the values obtained by the logarithmic decrement of damping considering the decay experimentally measured in different cycles;

(iii) the equivalent stiffness of the isolation system, evaluated considering the (undamped) free vibrations of the 2-DOF system.

The points representing the equivalent stiffness of (half) isolation system versus the maximum relative displacement of the same system reached in many steady-state harmonic tests are reported in Figure 9(a), where also the regression curve is shown. The corresponding variation of the equivalent stiffness is shown in Figure 9(b). It should be noted that it was not possible to reach the design displacement $(130 \mathrm{~mm})$ to avoid the damage of the steel superstructure.

On the basis of the above results, the points in Figure 10, representing the strength versus the maximum displacement of (half) isolation system of each test, were obtained calculating the strength as the product of the equivalent (secant) stiffness by the corresponding maximum displacement. Then, the regression curve was derived; in particular,
TABLE 5: Shaking table tests (steady-state harmonic motion).

\begin{tabular}{lcc}
\hline Test & Frequency $(\mathrm{Hz})$ & $\begin{array}{c}\text { Peak acceleration of shaking table } \\
\left(\mathrm{m} / \mathrm{s}^{2}\right)\end{array}$ \\
\hline 1 & 1.00 & 0.847 \\
2 & 1.00 & 1.206 \\
3 & 1.00 & 1.945 \\
4 & 1.00 & 2.586 \\
5 & 0.60 & 1.225 \\
\hline
\end{tabular}

the dashed part of the curve was extrapolated assuming a friction coefficient of about $6 \%$ for the sliders, to take into account the moderate value of pressure. For a useful comparison, the secant stiffness $K_{\mathrm{si}}(=220 \mathrm{kN} / \mathrm{m})$ of a single elastomeric bearing was also shown, which was provided by the manufacturer (FIP Industriale S.p.A., Italy) together with equivalent viscous damping of about $15 \%$ (see Section 2) on the basis of qualification tests conducted by the same manufacturer for many elastomeric bearings with similar material characteristics. It is evident that, especially for rather low values of displacement (first branch of the regression curve), $K_{\mathrm{si}}$ is much lower than the equivalent stiffness of (half) isolation system (see also Table 6), which includes also the contribution of (two) sliding bearings.

To check the reliability of the viscoelastic (VE) model of the isolated structure in simulating the response under steady-state forced and following free vibrations, the isolated structure was idealized as a 2-DOF system, assuming the damping matrix as a linear combination of mass matrix and stiffness matrix with reference to the two vibration modes (Rayleigh damping). Then, the experimental and numerical responses of the isolation system and superstructure were compared: for example, with reference to characterization test $4(\xi=13.5 \%)$, the curves are shown in Figure 11 .

As expected, the response of the isolation system was described with good accuracy, but the experimental response of the superstructure was underestimated. This can be in part ascribed to the very low value of the damping factor of the actual steel frame, especially in comparison with the damping factor identified for the isolation system, including also the effects of the friction of the sliders. 
TABLE 6: Results of characterization by shaking table tests (free vibrations of isolated structure).

\begin{tabular}{lcccc}
\hline Test & $\begin{array}{c}\text { Displacement range of isolator system } \\
(\mathrm{mm})\end{array}$ & Period (s) & Damping factor (\%) & $\begin{array}{c}\text { Equivalent stiffness of the isolation system } \\
(\mathrm{kN} / \mathrm{m})\end{array}$ \\
\hline 1 & $5.3-2.8$ & 0.42 & 8.3 & 2824.0 \\
2 & $13.1-5.0$ & 0.51 & 13.5 & 1570.8 \\
3 & $20.6-9.2$ & 0.58 & 11.7 & 1154.8 \\
4 & $33.0-13.4$ & 0.64 & 13.5 & 902.6 \\
5 & $7.7-4.3$ & 0.46 & 8.2 & 2107.4 \\
\hline
\end{tabular}

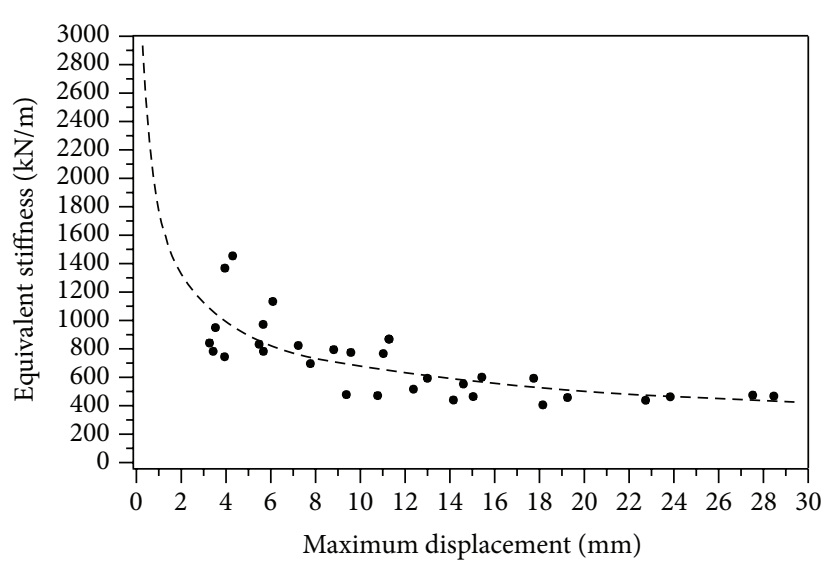

(a)

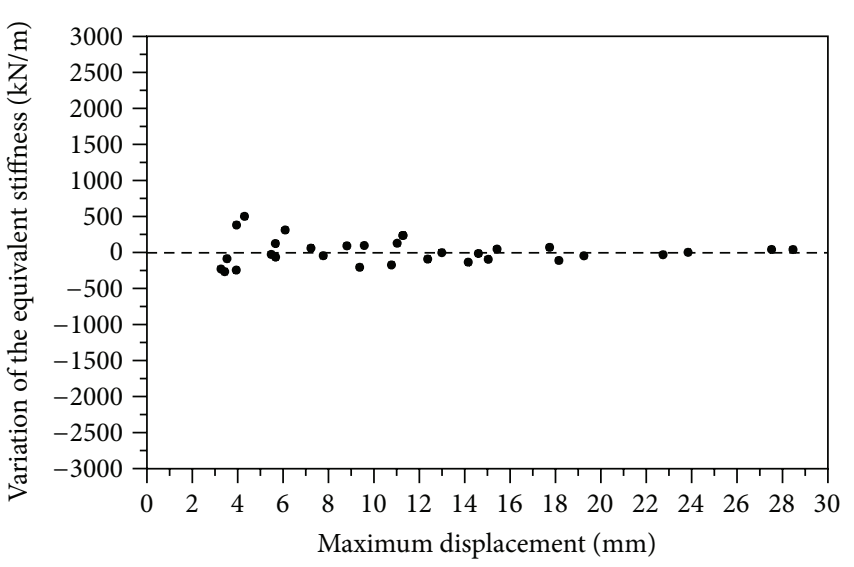

(b)

FIGURE 9: Equivalent stiffness of (half) isolation system versus maximum relative displacement: experimental points and regression curve (a); variation of the equivalent stiffness (b).

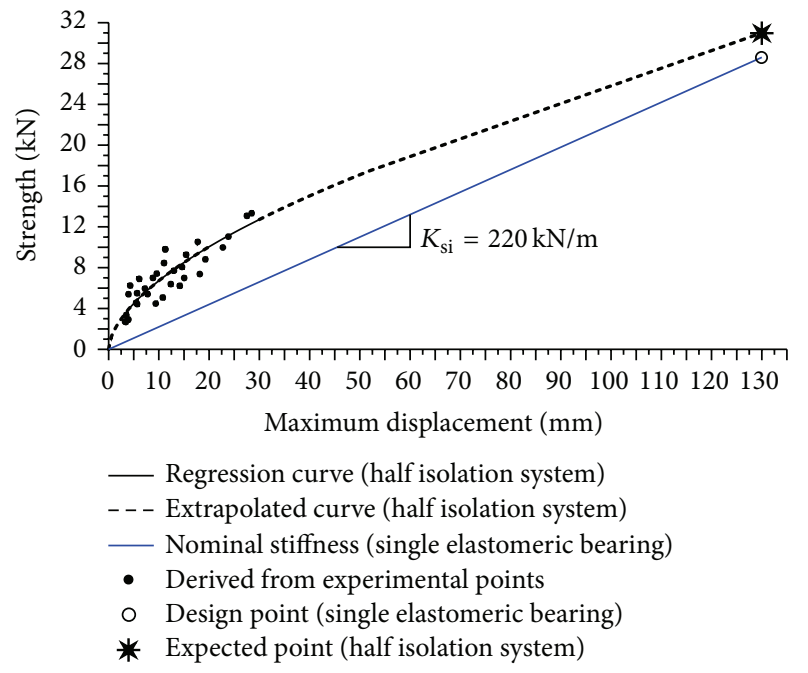

FigURE 10: Strength-displacement relationship of (half) isolation system.

\section{Shaking Table Tests of the Isolated Structure}

4.1. Tests' Inputs. A set of seven waveforms, which are compatible with the new Italian Seismic Code (NTC 2008) [10], was selected from the European Strong-Motion Database (Ambraseys et al. [11]) using REXEL v3.4 beta (Iervolino et al. [12]) for the DPC-ReLUIS research project. This selection is representative of regions in Italy with a moderate to high seismic risk. As a geometry scale factor $S_{L}=1 / 3$ and an elastic moduli scale factor $S_{E}=1$ were assumed to satisfy the dynamic similitude requirements, the selected earthquakes were compressed in time by a time scale $S_{T}$ of $1 / \sqrt{ } 3$. The $5 \%$ damped-scaled horizontal spectra are shown in Figure 12. The ground motion specifics relative to the original and scaled records are provided in Table 7.

The selected horizontal accelerograms are in compliance with the Italian Seismic Code for the life safety limit state of a strategic structure (functional class IV [10]) located in Naples, Italy $\left(14.2767^{\circ}\right.$ longitude, $40.863^{\circ}$ latitude), on soil type A (stiff soil or rock) with a nominal life of 100 years (which corresponds to a 1898-year return period according to the code). Further details about the ground motion selection can be found in a shaking table investigation by Calabrese et al. [13].

The three ground motions labelled as LAZ, CAM, and CAT in Table 7 were selected, among the seven waveforms mentioned above, for this study. For brevity, in the following discussion the attention is focused on the results obtained under the two records CAM and CAT, labelled also as motions 290 and 287, which induced displacements larger than those due to record LAZ. In particular, different intensities were considered increasing proportionally the acceleration of the records CAM and CAT: 290@100\% and 290@150\%; 287@100\%,287@150\%, and 287@175\%. 
TABLE 7: Ground motions, specifics, and significant parameters.

\begin{tabular}{|c|c|c|c|c|c|c|c|c|c|}
\hline \multirow{2}{*}{ Record } & \multirow{2}{*}{ Waveform ID } & \multirow{2}{*}{ Station ID } & \multirow{2}{*}{ Date (dd/mm/yy) } & \multirow{2}{*}{ SF } & \multirow{2}{*}{$M_{w}$} & \multirow{2}{*}{$R(\mathrm{~km})$} & \multicolumn{3}{|c|}{ Full scale earthquake } \\
\hline & & & & & & & $\operatorname{PGA}\left(\mathrm{m} / \mathrm{s}^{2}\right)$ & $\mathrm{PGV}(\mathrm{cm} / \mathrm{s})$ & PGD $(\mathrm{cm})$ \\
\hline Bingol (BIN) & $7142 y a$ & ST539 & $01 / 05 / 2003$ & 0.87 & 6.3 & 14 & 2.55 & 18.29 & 3.25 \\
\hline Friuli (FRI) & $55 \mathrm{xa}$ & ST20 & 06/05/1976 & 0.72 & 6.5 & 23 & 2.55 & 15.25 & 9.29 \\
\hline Montenegro (MON) & $200 y a$ & ST68 & $15 / 04 / 1979$ & 1.01 & 6.9 & 65 & 2.55 & 12.87 & 9.60 \\
\hline Etolia (ETO) & $428 y a$ & ST169 & $18 / 05 / 1988$ & 1.47 & 5.3 & 23 & 2.55 & 12.46 & 6.06 \\
\hline Lazio Abruzzo (LAZ) & 372 уа & ST274 & 07/05/1984 & 2.06 & 5.9 & 68 & 2.55 & 15.02 & 6.80 \\
\hline Campano Lucano (CAM) & $290 y a$ & ST96 & 23/11/1980 & 0.80 & 6.9 & 32 & 2.55 & 44.10 & 16.20 \\
\hline Campano Lucano (CAT) & $287 y a$ & ST93 & 23/11/1980 & 1.43 & 6.9 & 23 & 2.55 & 43.90 & 14.00 \\
\hline
\end{tabular}

$\mathrm{SF}=$ scale factor $M_{w}=$ magnitude; $R=$ epicentral distance.

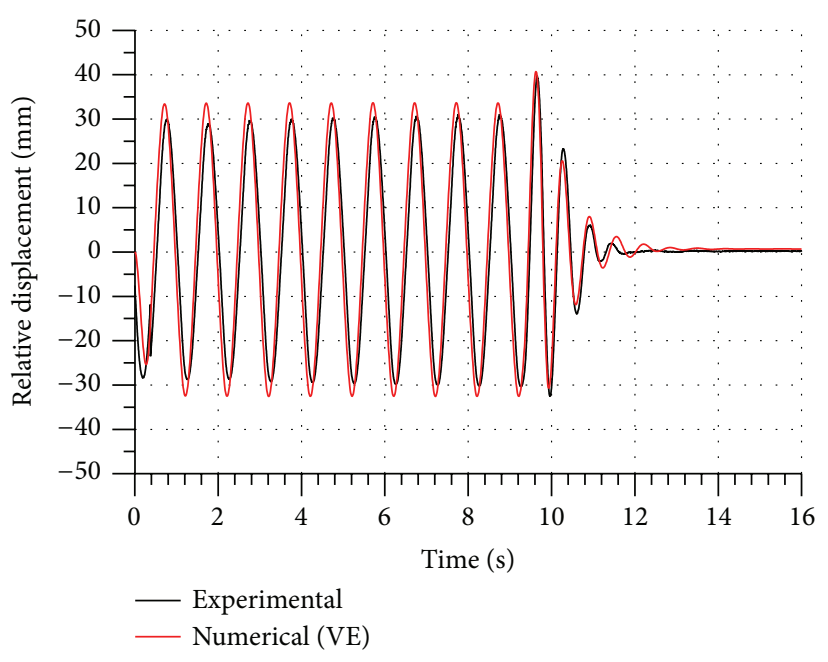

(a) Isolation system

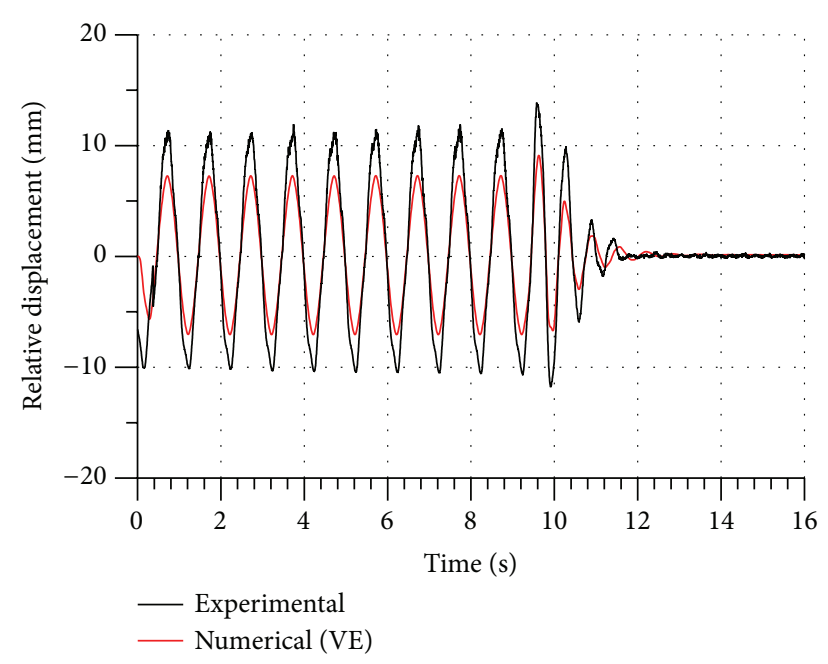

(b) Superstructure

FIGURE 11: Experimental and numerical (VE isolation model) steady-state forced and free vibrations of the isolation system and superstructure (characterization test 4 ).
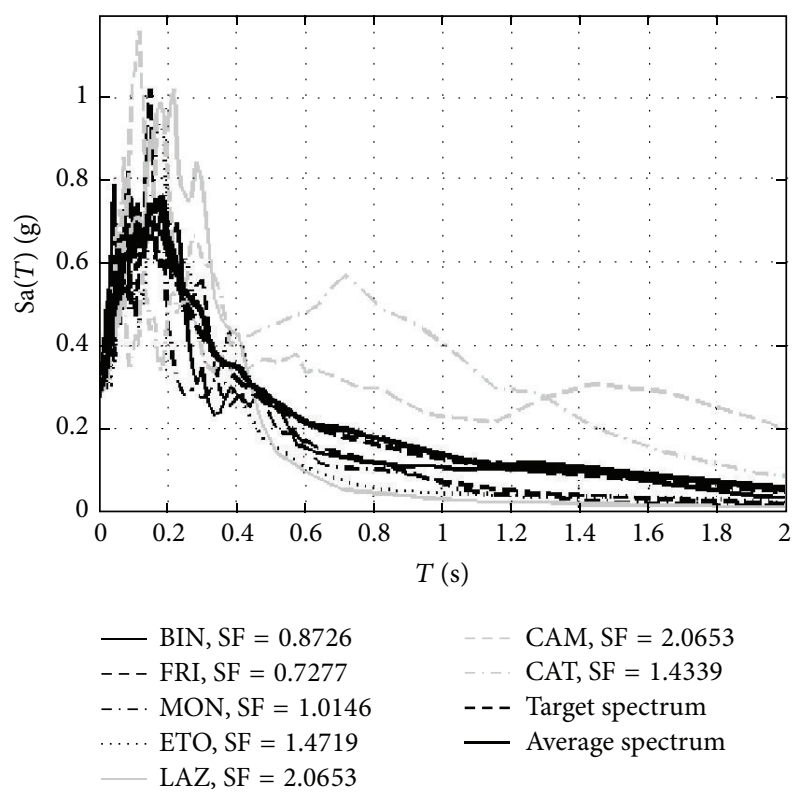

FIGURE 12: Scaled ground motion spectra and target spectrum according to NTC $2008\left(S_{T}=1 / \sqrt{ } 3\right)$.
4.2. Analytical Modelling of the Isolated Structure. The numerical simulations have been performed using SAP2000 [14]. Columns and girders were idealized by an elastic beam model, while the isolation system was idealized using alternatively each of the following analytical models: viscoelastic (VE), bilinear (BL), or trilinear (TL) (Figure 13). The pin connection at the top of the columns was also considered in the structural model. In particular, when using BL and TL models, the damping for the superstructure was considered negligible in comparison to that of the isolation system model.

4.3. Results of Investigation. The experimental results obtained for the isolated structure subjected to each of the selected motions (in particular, 290 and 287 of different intensity), which were applied to the shaking table, were compared with the numerical response obtained using, one at a time, the three considered models (VE, BL, and TL) of the isolation system. For brevity, the main results are reported in Figures 14-20, where the numerical curves were obtained by a suitable calibration of the characteristic parameters (i.e., $K_{\mathrm{si}}, K_{0}, F_{y}, F_{y 1}$, and $F_{y 2}$ ) of half isolation model, consisting 


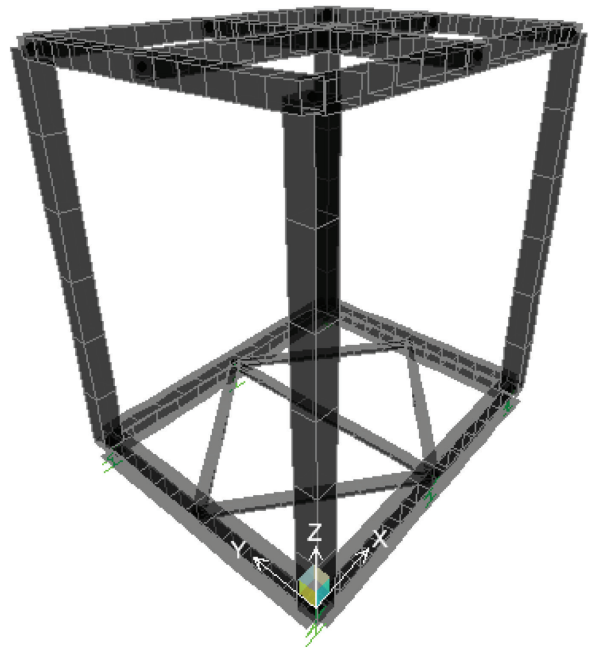

(a) Isolated structure

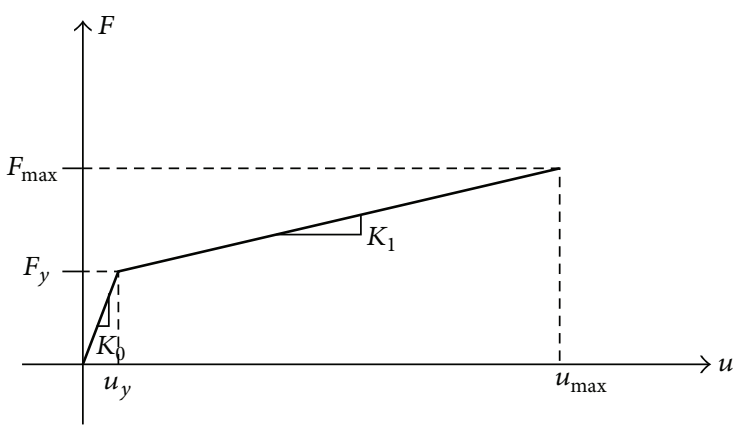

(c) Isolation system: bilinear (BL) model

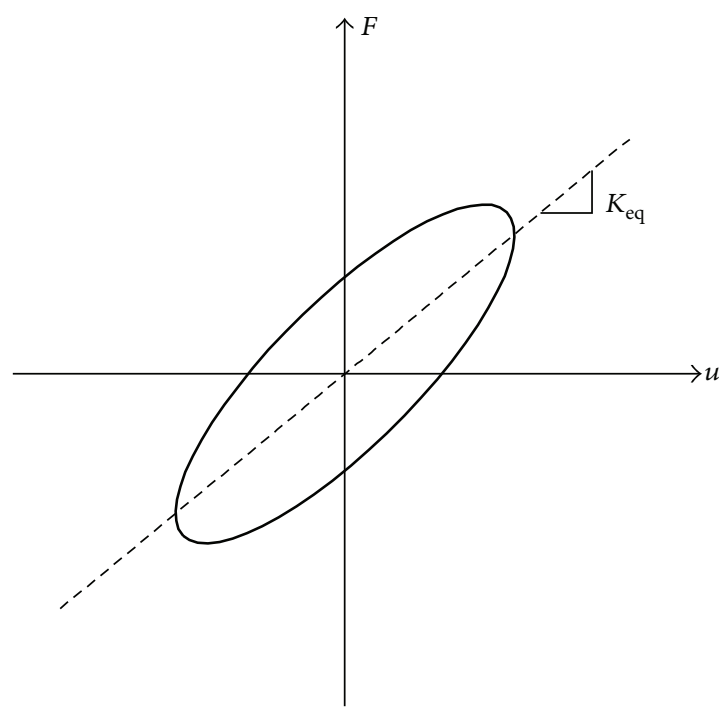

(b) Isolation system: viscoelastic (VE) model

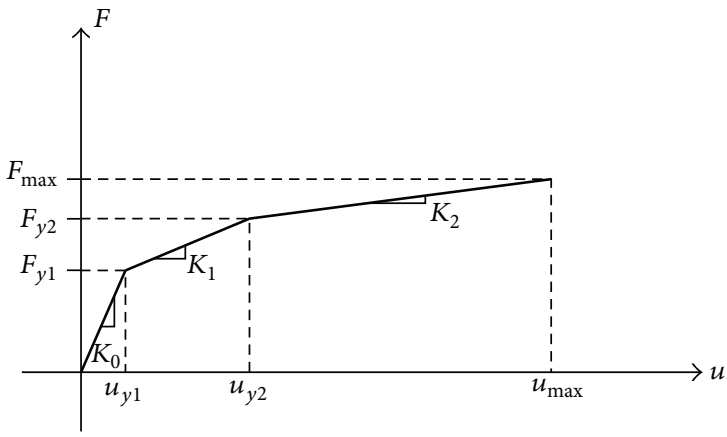

(d) Isolation system: trilinear (TL) model

FIGURE 13: Modelling of the isolated structure.

of one of the two elastomeric bearings and two of the four sliders.

More precisely, the numerical curves assuming VE model are shown in Figure 14; the numerical curves assuming a BL model are shown in Figure 15, while the analogous curves assuming a TL model are shown in Figures 16, 17 and 18 (motion 287), and Figures 19 and 20 (motion 290). In particular, all the curves for TL isolation model were obtained assuming the same values of the characteristic parameters of this model, to check the reliability of the model under different waveform and intensity of the motions.

As can be observed, the VE model, at least in the range of displacements measured during the shaking table tests, was capable of simulating with good accuracy the response of the isolation system, providing that a suitable calibration of the model was adopted. It should be noted that this calibration requires an iterative procedure, because an equivalent viscous damping ratio can be defined with reference to a steadystate response assuming a value of the expected maximum displacement, which is initially unknown. However, the numerical results for the superstructure, omitted for brevity, emphasized an underestimation of the experimental displacement. This may be expected because, assuming a proportional viscous damping matrix (Rayleigh damping), the relative displacement of the superstructure is affected by the high damping of the isolation system (15\% at the design displacement), which is relatively high in comparison with the rather low damping of the superstructure (about $0.65 \%$ ).

On the other hand, although the performed tests are limited and do not allow a general conclusion, it can be observed that $\mathrm{BL}$ and TL models overestimated the peak response of the isolation system (even about $40 \%$ ); however, they underestimated that of the superstructure (even about $35 \%$ ), as noted above for VE model. In addition, their calibration, especially for TL model, was more complex due to a greater number of parameters involved in comparison to the two parameters (i.e., equivalent stiffness and damping factor with reference to the expected maximum displacement) required to identify the VE model. However, it should be noted that, for displacements larger than those investigated in this study, BL and TL models may be more suitable.

4.4. Effectiveness of the Isolation System. To check the effectiveness of the isolation system, the experimental response of the isolated structure was compared with the numerical (undamped) response of the fixed-base structure, which, as 


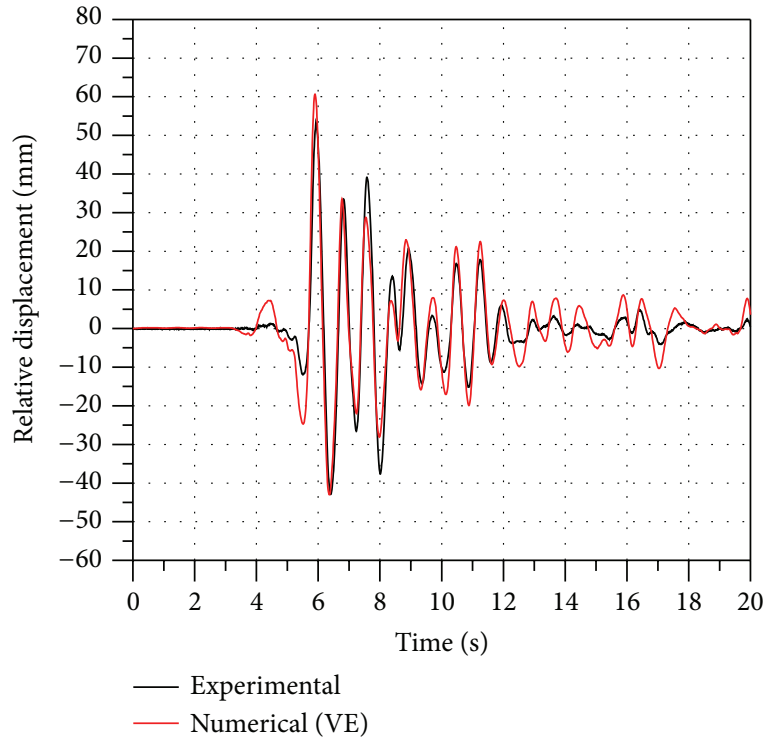

(a) Motion 287@175\% (VE isolation model: $K_{\mathrm{si}}=345 \mathrm{kN} / \mathrm{m}$; $\xi=25 \%$ )

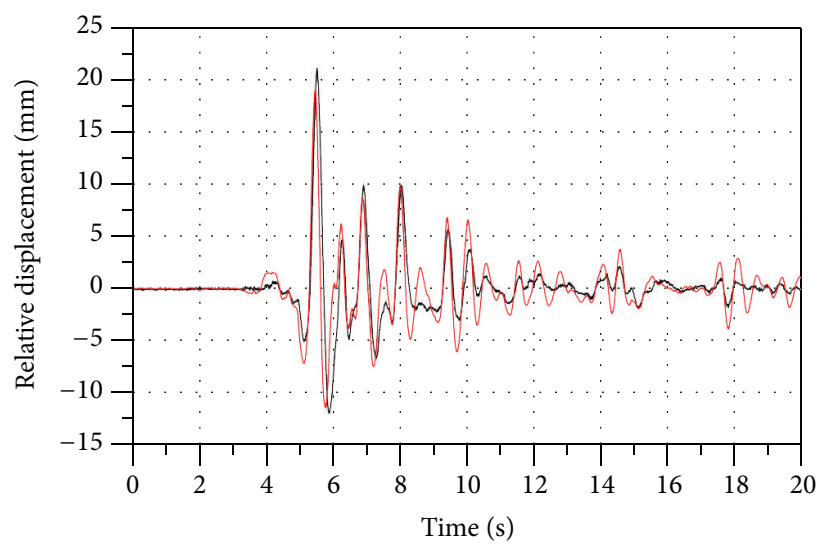

- Experimental

- Numerical (VE)

(c) Motion 287@100\% (VE isolation model: $K_{\mathrm{si}}=800 \mathrm{kN} / \mathrm{m}$; $\xi=13 \%$ )

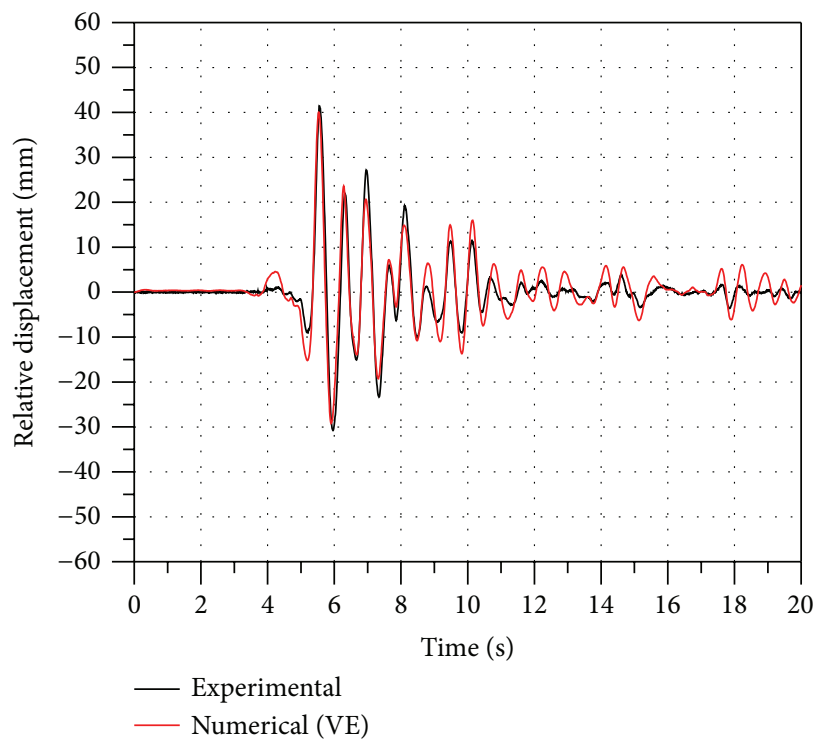

(b) Motion 287@150\% (VE isolation model: $K_{\mathrm{si}}=520 \mathrm{kN} / \mathrm{m} ; \xi=20 \%$ )

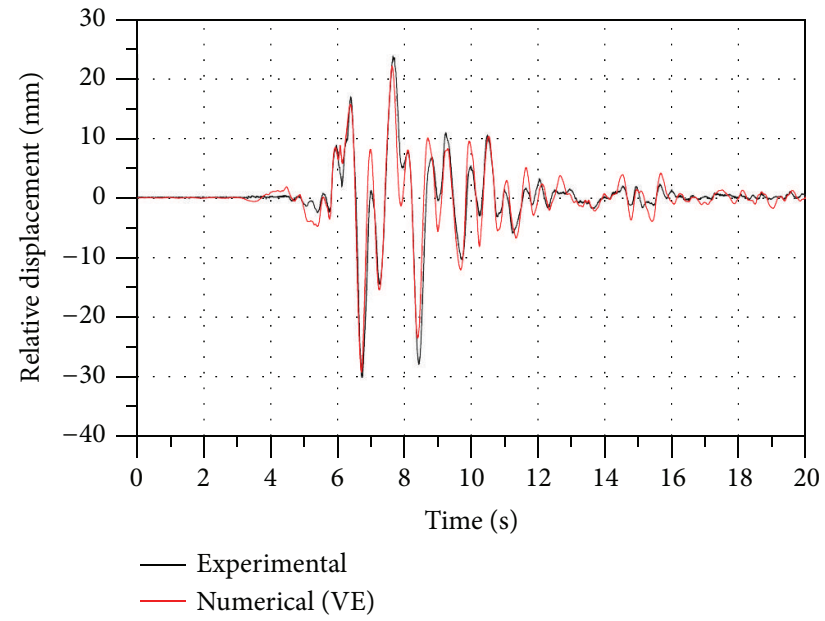

(d) Motion 290@150\% (VE isolation model: $K_{\mathrm{si}}=580 \mathrm{kN} / \mathrm{m} ; \xi=16 \%$ )

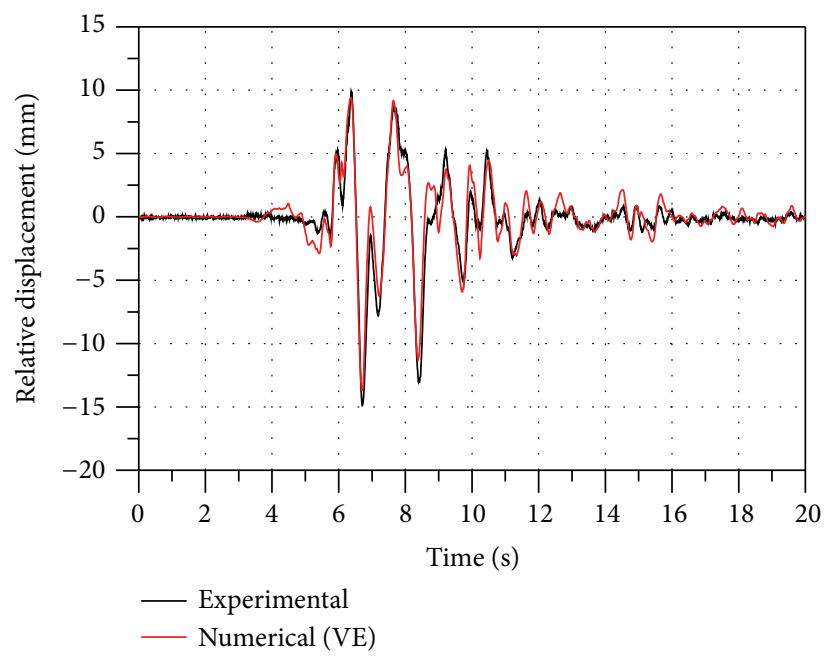

(e) Motion 290@100\% (VE isolation model: $K_{\mathrm{si}}=650 \mathrm{kN} / \mathrm{m}$; $\xi=20 \%$ )

Figure 14: Experimental and numerical (VE isolation model) results for the isolation system. 


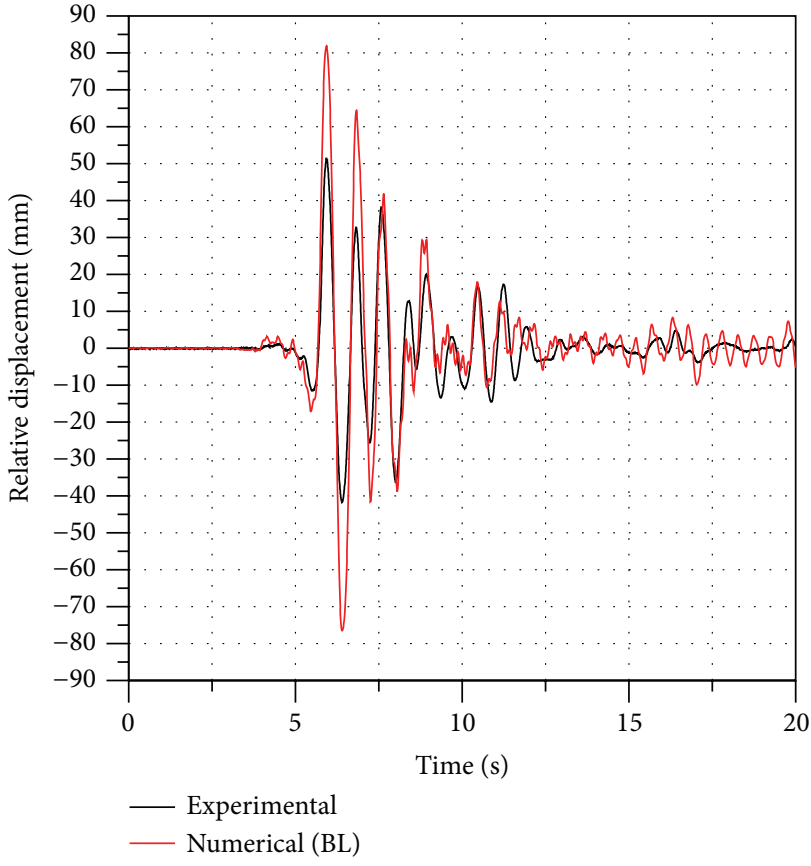

(a) Isolation system

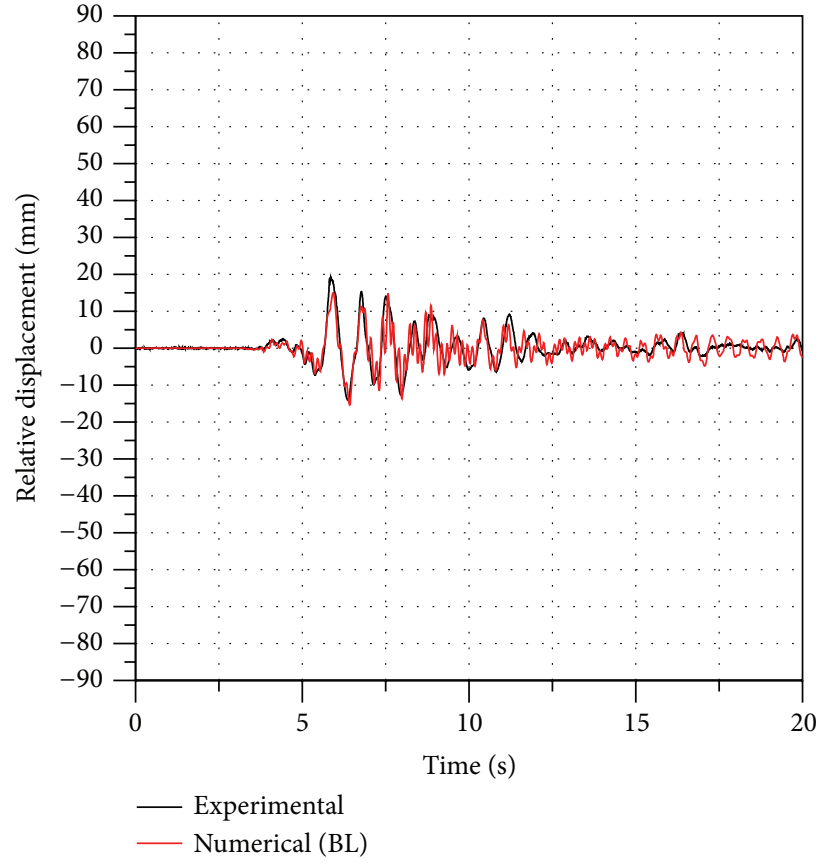

(b) Superstructure

FIGURE 15: Experimental and numerical relative displacements for motion 287@175\% (BL isolation model: $K_{0}=1000 \mathrm{kN} / \mathrm{m}, K_{1} / K_{0}=0.22$, and $\left.F_{y}=7 \mathrm{kN}\right)$.

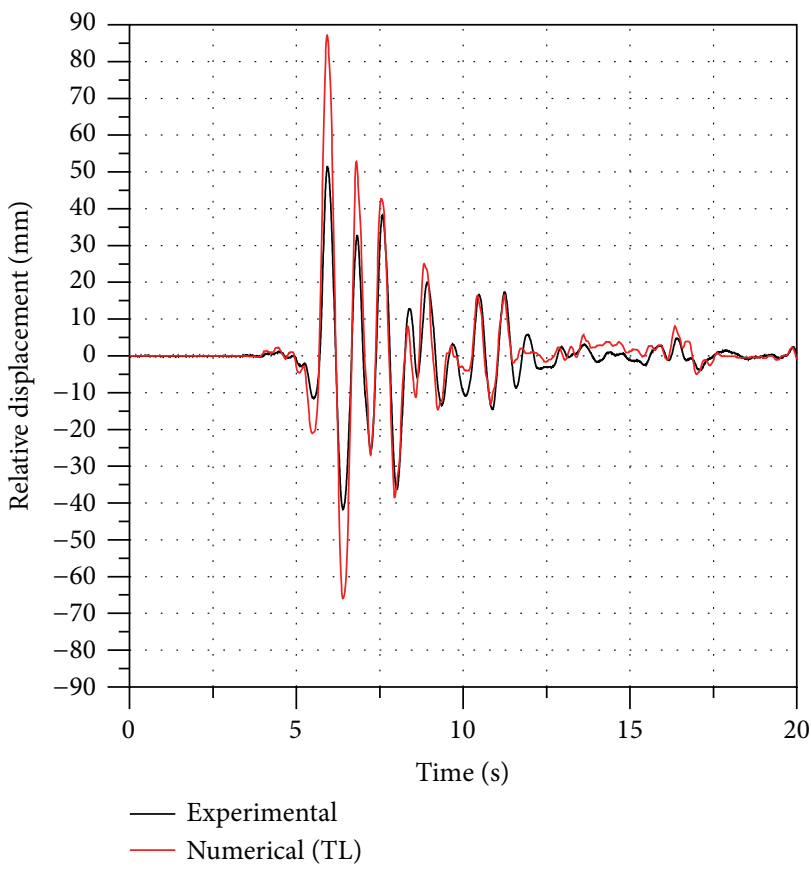

(a) Isolation system

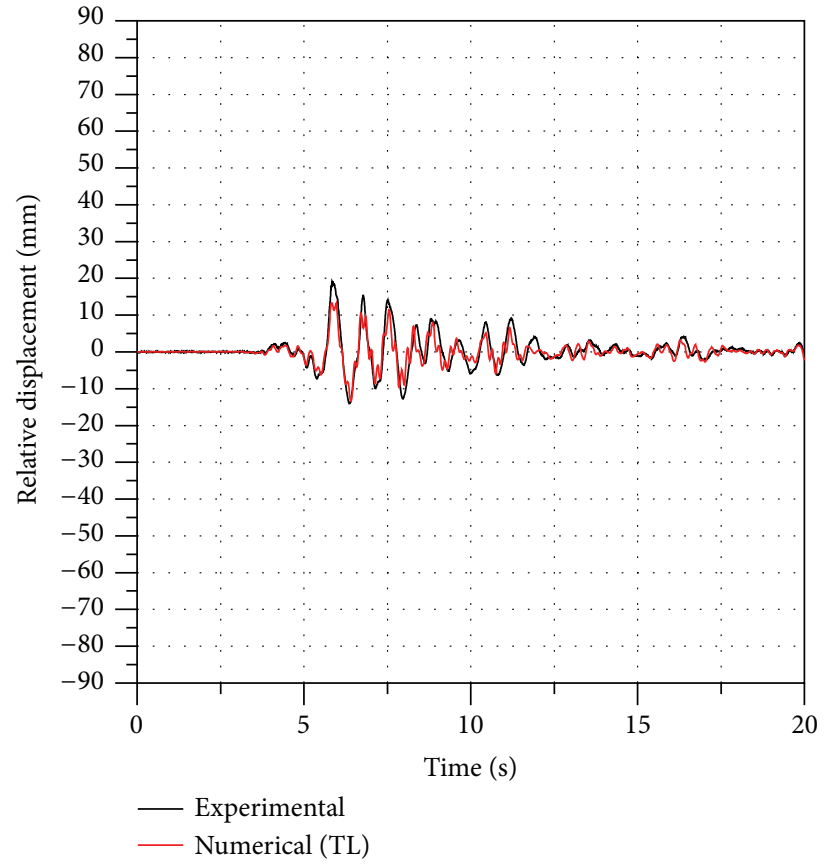

(b) Superstructure

Figure 16: Experimental and numerical relative displacements for motion $287 @ 175 \%$ (TL isolation model: $K_{0}=2000 \mathrm{kN} / \mathrm{m}, K_{1} / K_{0}=0.20$, $K_{2} / K_{0}=0.10, F_{y 1}=3 \mathrm{kN}$, and $\left.F_{y 2}=13 \mathrm{kN}\right)$. 


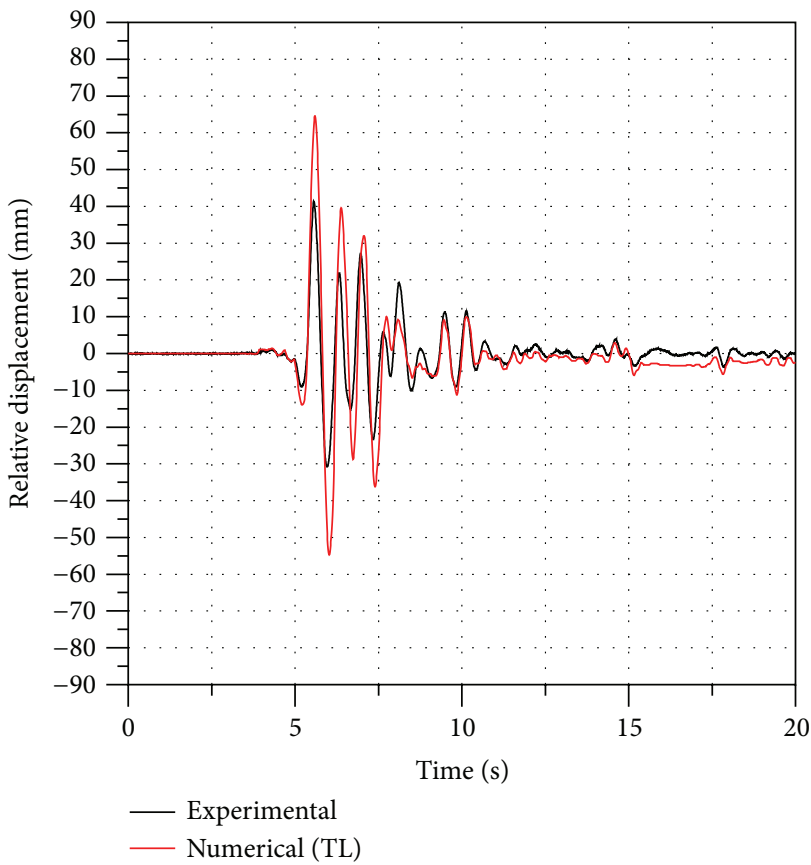

(a) Isolation system

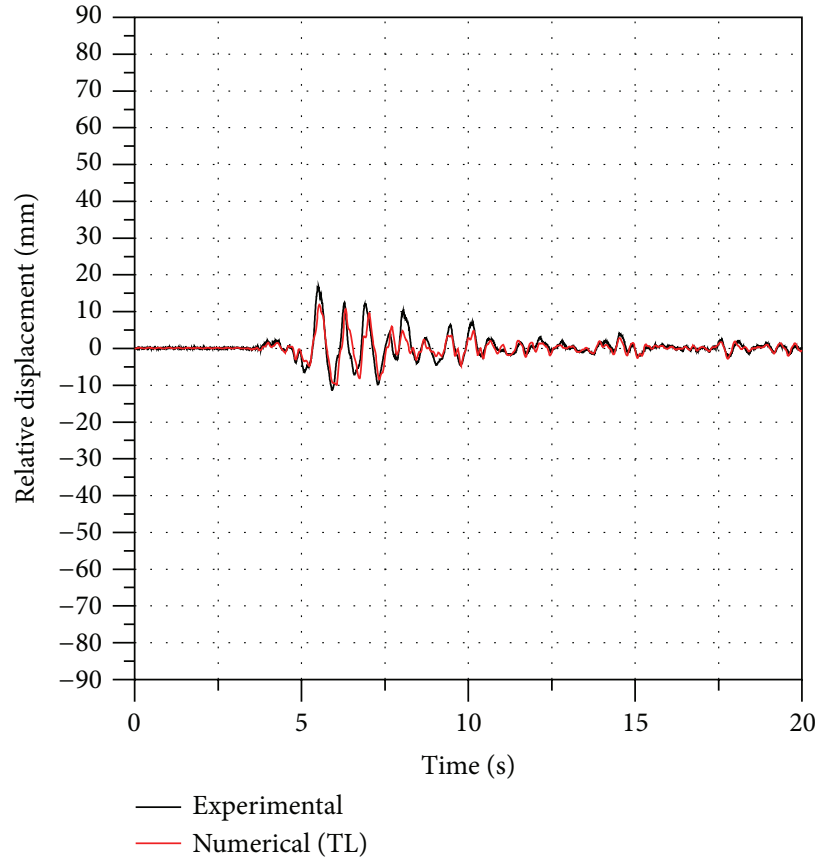

(b) Superstructure

Figure 17: Experimental and numerical relative displacements for motion 287@150\% (TL isolation model: $K_{0}=2000 \mathrm{kN} / \mathrm{m}, K_{1} / K_{0}=0.20$, $K_{2} / K_{0}=0.10, F_{y 1}=3 \mathrm{kN}$, and $\left.F_{y 2}=13 \mathrm{kN}\right)$.

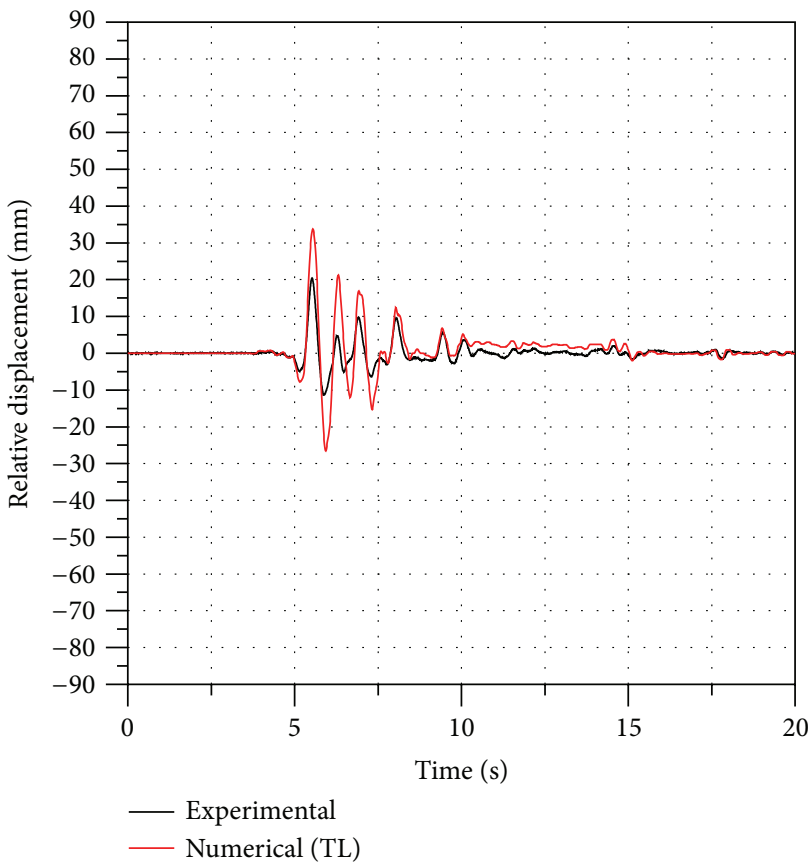

(a) Isolation system

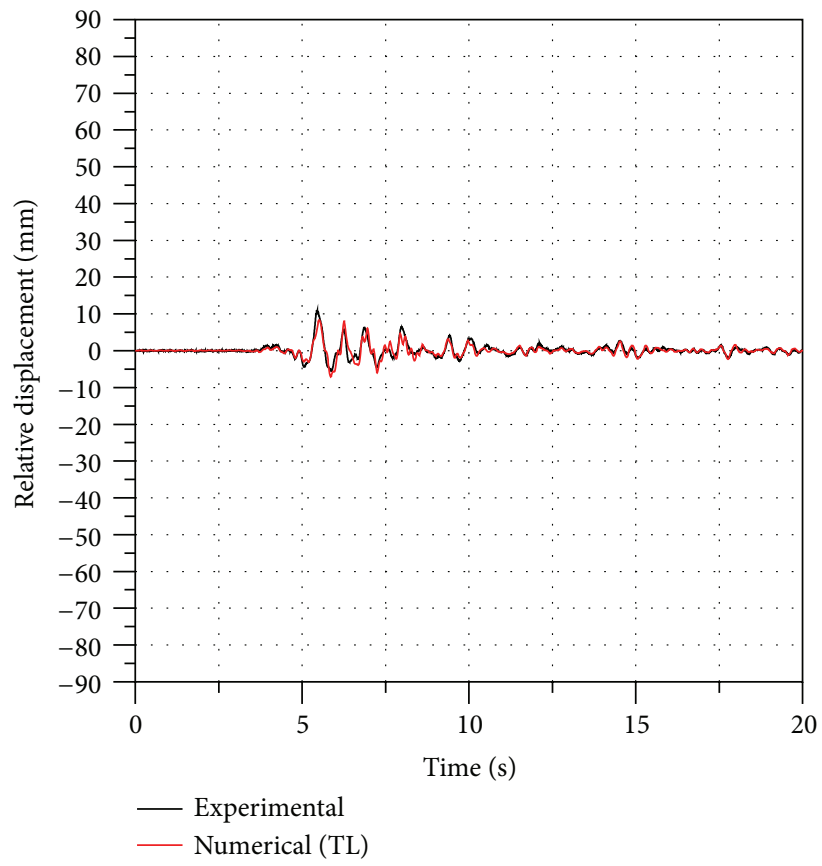

(b) Superstructure

FIGURE 18: Experimental and numerical relative displacements for motion 287@100\% (TL isolation model: $K_{0}=2000 \mathrm{kN} / \mathrm{m}, K_{1} / K_{0}=0.20$, $K_{2} / K_{0}=0.10, F_{y 1}=3 \mathrm{kN}$, and $\left.F_{y 2}=13 \mathrm{kN}\right)$. 


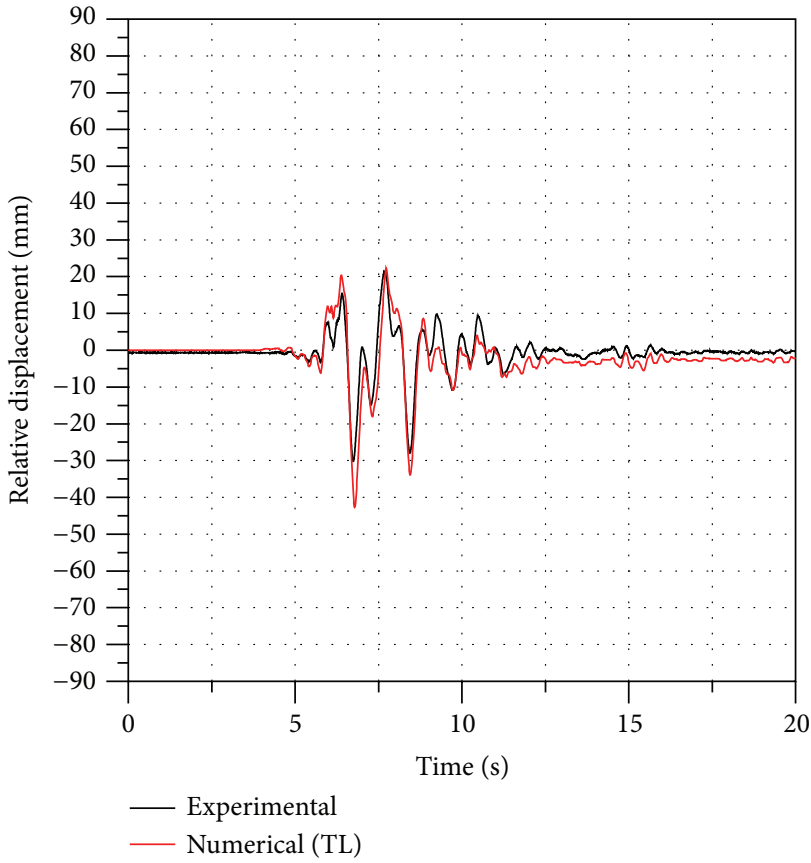

(a) Isolation system

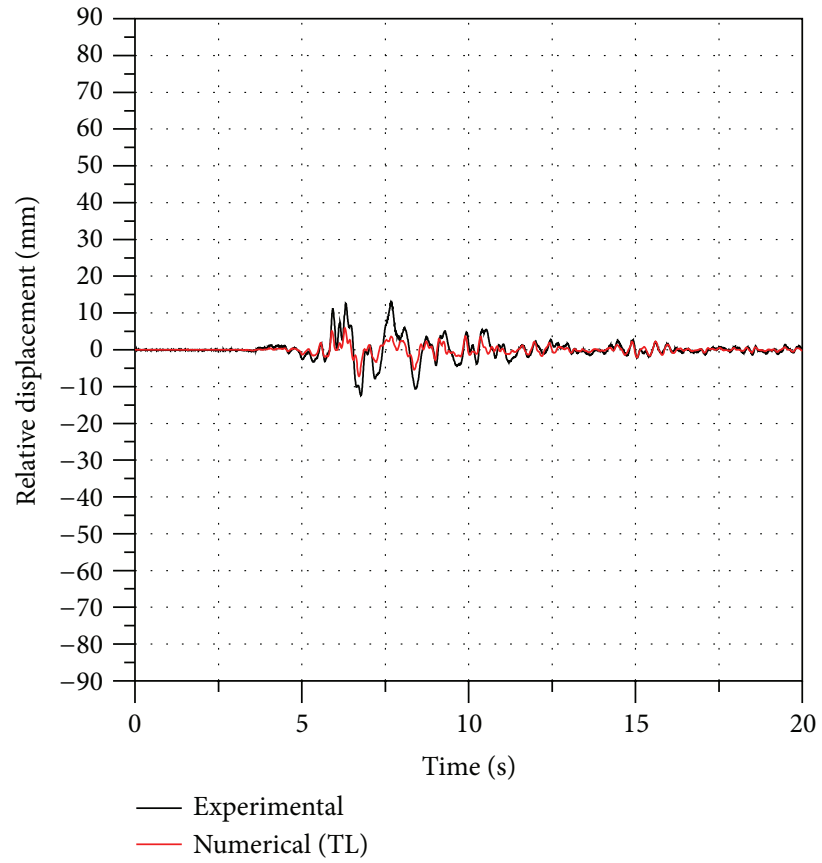

(b) Superstructure

Figure 19: Experimental and numerical relative displacements for motion $290 @ 150 \%$ (TL isolation model: $K_{0}=2000 \mathrm{kN} / \mathrm{m}, K_{1} / K_{0}=0.20$, $K_{2} / K_{0}=0.10, F_{y 1}=3 \mathrm{kN}$, and $\left.F_{y 2}=13 \mathrm{kN}\right)$.

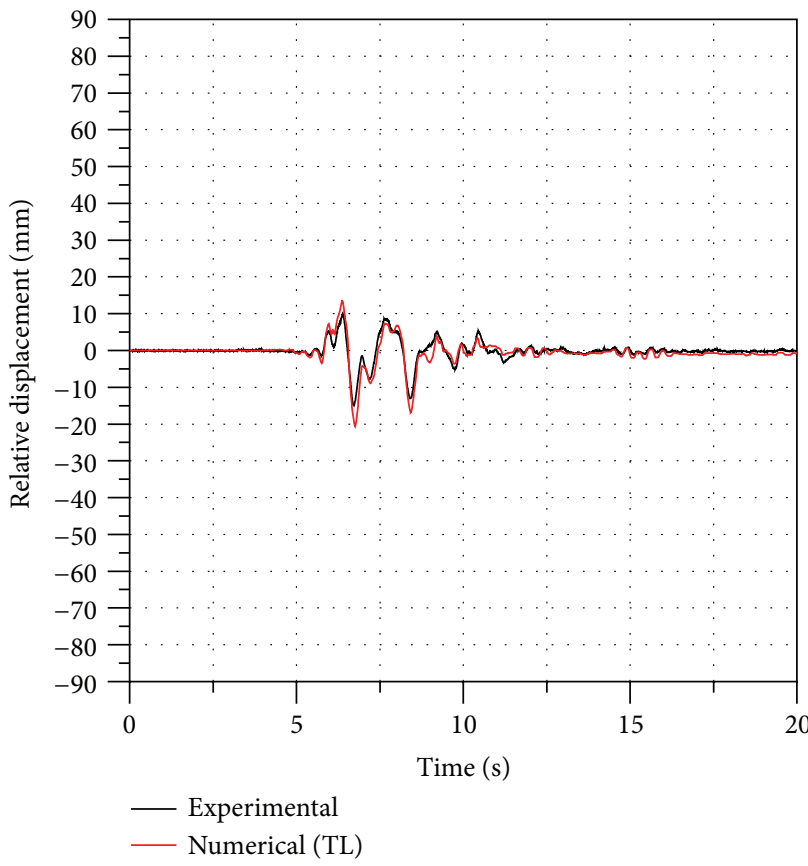

(a) Isolation system

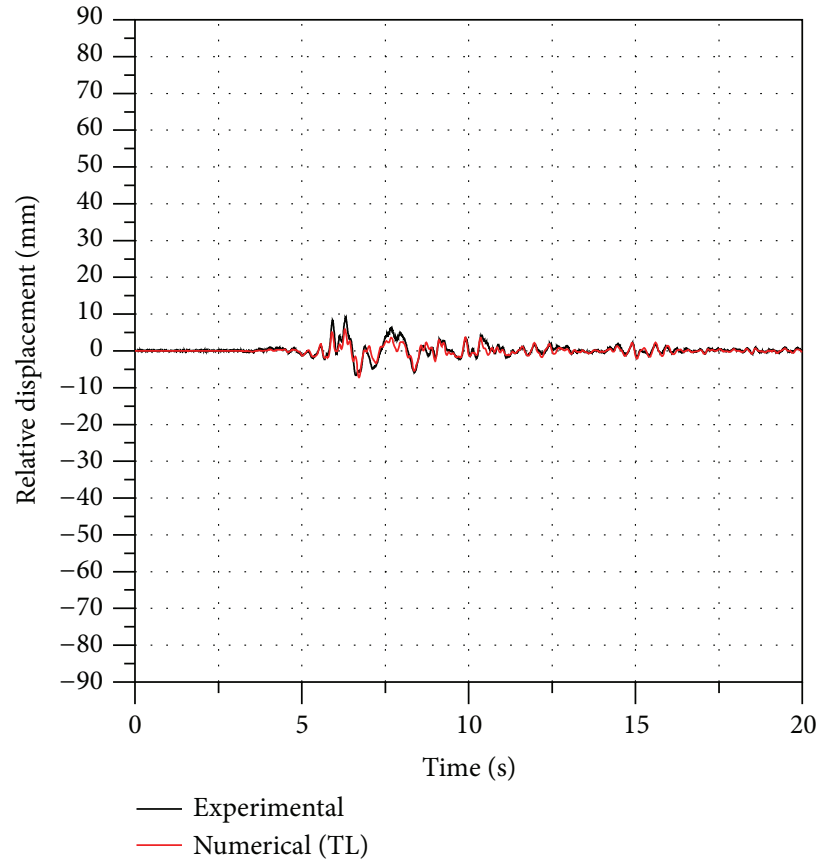

(b) Superstructure

Figure 20: Experimental and numerical relative displacements for motion $290 @ 100 \%$ (TL isolation model: $K_{0}=2000 \mathrm{kN} / \mathrm{m}, K_{1} / K_{0}=0.20$, $K_{2} / K_{0}=0.10, F_{y 1}=3 \mathrm{kN}$, and $\left.F_{y 2}=13 \mathrm{kN}\right)$. 
TABLE 8: Isolated structure versus fixed-base undamped structure.

\begin{tabular}{lccc}
\hline Motion & $\begin{array}{c}\Delta_{\mathrm{BI}, \max } \\
(\mathrm{mm})\end{array}$ & $\begin{array}{c}\Delta_{\mathrm{FB}, \max } \\
(\mathrm{mm})\end{array}$ & $\begin{array}{c}\text { Reduction factor } \\
\left(\Delta_{\mathrm{BI}, \max } / \Delta_{\mathrm{FB}, \max }\right)\end{array}$ \\
\hline $287 @ 100 \%$ & 8.35 & 23.07 & 0.36 \\
$287 @ 150 \%$ & 11.92 & 34.61 & 0.34 \\
$287 @ 175 \%$ & 13.02 & 40.37 & 0.32 \\
$290 @ 100 \%$ & 7.26 & 13.02 & 0.56 \\
$290 @ 150 \%$ & 10.62 & 19.53 & 0.54 \\
\hline
\end{tabular}

$\Delta_{\mathrm{BI}, \max }=$ peak interstorey drift of isolated structure.

$\Delta_{\mathrm{FB}, \max }=$ peak interstorey drift of fixed-base structure.

already noted, presented very low damping (about 0.65\%) and behaved elastically. A summary of the results is reported in Table 8, where the effectiveness of the isolation system is proved by reduction factor values rather lower than 1 . It should be noted that even though the reduction factor is calculated with reference to the interstorey drift of the steel superstructure, supposed to be isolated or fixed-base, the same reduction can be assumed for the stresses because of the elastic behaviour of the steel structure.

\section{Conclusions}

The behaviour of the isolated structure equipped with an in-parallel combination of steel-PTFE sliding bearings and elastomeric bearings was tested under both controlleddisplacement (harmonic) motion and earthquake ground motions of different intensity.

The first set of tests allowed the characterization of the isolation system, in particular its force-displacement relationship. Modelling the isolated structure as a 2-DOF system with VE behaviour (Rayleigh damping), the experimental displacement time-history (steady-state and free vibrations) was described with good accuracy for the isolation system, but it was underestimated for the superstructure due to the very low damping of the actual steel framed structure.

A further objective was to evaluate the reliability of different numerical models of the isolation system (VE, $\mathrm{BL}$, and TL, commonly used) in simulating the dynamic response of the examined structure. The comparison between experimental and numerical curves showed that the VE model, at least in the range of displacements measured during the shaking table tests, was capable of simulating with good accuracy the response of the isolation system, provided that a suitable calibration of the model was adopted. On the other hand, BL and TL models overestimated the peak response of the isolation system. As expected, all the isolation models underestimated the response of the steel superstructure, which, as said above, actually presented very low damping.

Finally, the effectiveness of the isolation system was shown comparing the experimental response of the isolated structure with the numerical response of the fixed-base steel structure, whose damping was very low (0.65\%).

\section{Conflict of Interests}

The authors declare that there is no conflict of interests regarding the publication of this paper.

\section{Acknowledgments}

The work is part of a research which has been supported by the consortium ReLUIS (Italian network of earthquake engineering laboratories) with a grant by the Italian Emergency Agency (2010-2013 ReLUIS Executive Project-Task 2.3.2Development of New Technologies for Seismic Mitigation). The support of all the organizations is gratefully acknowledged. The steel-PTFE sliding bearings and elastomeric bearings were manufactured and provided for free by FIP Industriale S.p.A. (Padova, Italy). The company is gratefully acknowledged.

\section{References}

[1] F. Naeim and J. M. Kelly, Design of Seismic Isolated Structures: From Theory to Practice, John Wiley \& Sons, New York, NY, USA, 1999.

[2] F. Braga, M. Faggella, R. Gigliotti, and M. Laterza, "Nonlinear dynamic response of HDRB and hybrid HDRB-friction sliders base isolation systems," Bulletin of Earthquake Engineering, vol. 3, no. 3, pp. 333-353, 2005.

[3] M. Dolce, D. Cardone, and F. Croatto, "Frictional behavior of steel-PTFE interfaces for seismic isolation," Bulletin of Earthquake Engineering, vol. 3, no. 1, pp. 75-99, 2005.

[4] F. C. Ponzo, A. Di Cesare, D. Nigro, M. Simonetti, and G. Leccese, "Shaking table tests of a base isolated structure with double concave friction pendulums," in Proceedings of the NZSEE Annual Conference, Auckland, New Zealand, April 2014.

[5] S. Sorace, G. Terenzi, G. Magonette, and F. J. Molina, "Experimental investigation on a base isolation system incorporating steel-teflon sliders and pressurized fluid viscous spring dampers," Earthquake Engineering and Structural Dynamics, vol. 37, no. 2, pp. 225-242, 2008.

[6] F. Mazza and A. Vulcano, "Nonlinear response of RC framed buildings with isolation and supplemental damping at the base subjected to near-fault earthquakes," Journal of Earthquake Engineering, vol. 13, no. 5, pp. 690-715, 2009.

[7] F. Mazza and A. Vulcano, "Effects of near-fault ground motions on the nonlinear dynamic response of base-isolated r.c. framed buildings," Earthquake Engineering and Structural Dynamics, vol. 41, no. 2, pp. 211-232, 2012.

[8] F. Mazza, A. Vulcano, and M. Mazza, "Nonlinear dynamic response of RC buildings with different base isolation systems subjected to horizontal and vertical components of near-fault ground motions," Open Construction and Building Technology Journal, vol. 6, pp. 373-383, 2012.

[9] G. Magliulo, C. Petrone, V. Capozzi et al., "Shake table tests on infill plasterboard partitions," Open Construction and Building Technology Journal, vol. 6, no. 1, pp. 155-163, 2012.

[10] NTC, Nuove Norme Tecniche per le Costruzioni, DM 14 Gennaio 2008, Gazzetta Ufficiale n. 29 del 4 febbraio 2008-Supplemento Ordinario n. 30, 2008 (Italian).

[11] N. Ambraseys, P. Smit, R. Sigbjornsson, P. Suhadolc, and B. Margaris, Internet-Site for European Strong-Motion Data, European Commission, Research-Directorate General, Environment and Climate Program, 2002, http://www.isesd.hi is/ESD_Local/frameset.htm. 
[12] I. Iervolino, C. Galasso, and E. Cosenza, "REXEL: computer aided record selection for code-based seismic structural analysis," Bulletin of Earthquake Engineering, vol. 8, no. 2, pp. 339362, 2010.

[13] A. Calabrese, M. Spizzuoco, G. Serino, G. D. Corte, and G. Maddaloni, "Shaking table investigation of a novel, low-cost, base isolation technology using recycled rubber," Structural Control and Health Monitoring, vol. 22, no. 1, pp. 107-122, 2014.

[14] Computers and Structures, Analysis Reference Manual, SAP2000, Computers and Structures, Berkeley, Calif, USA, 2013. 

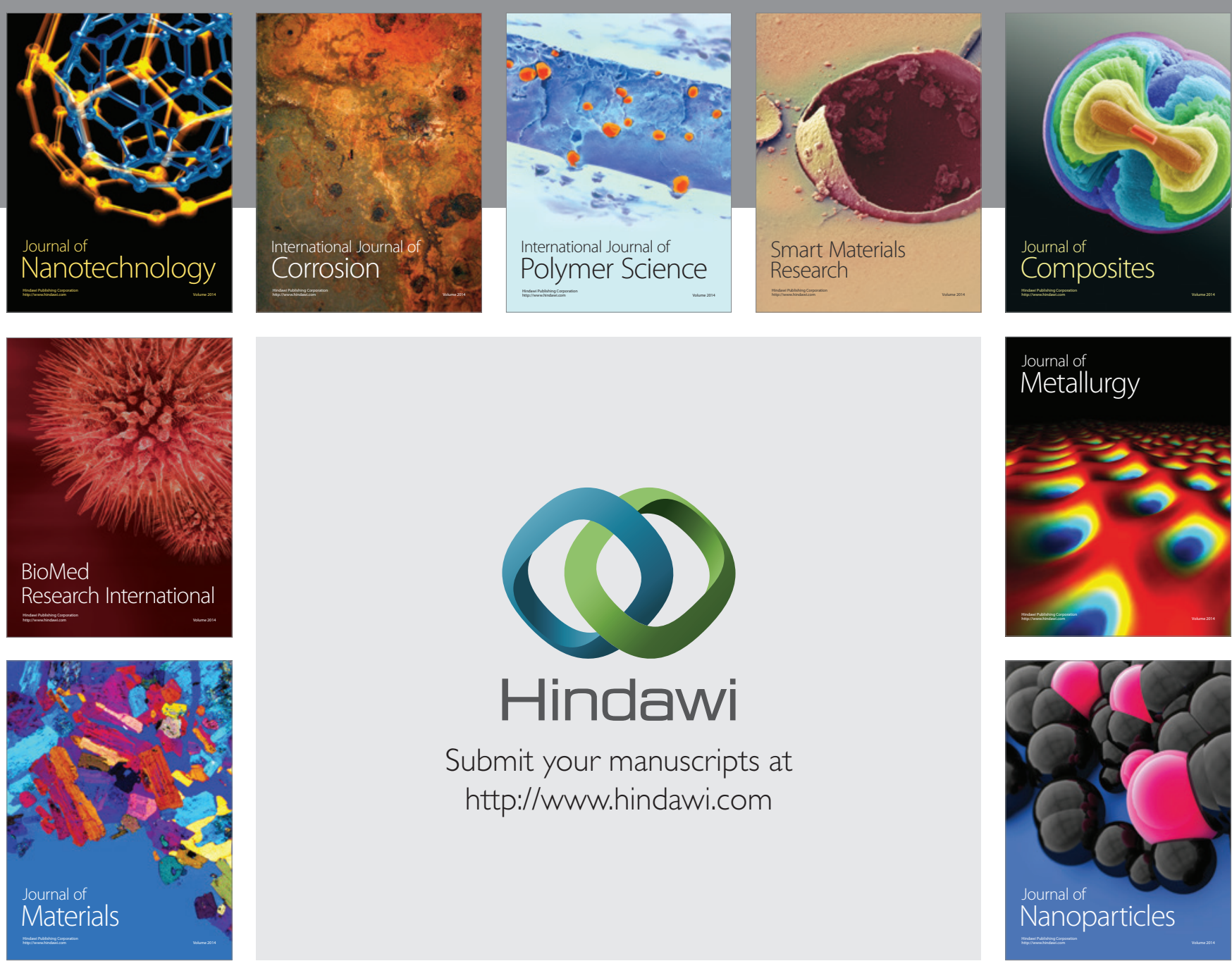

\section{Hindawi}

Submit your manuscripts at

http://www.hindawi.com

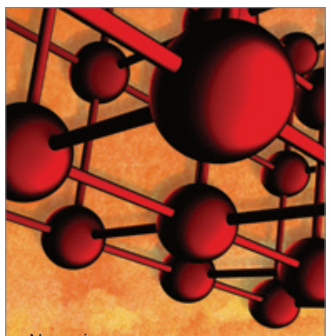

Materials Science and Engineering
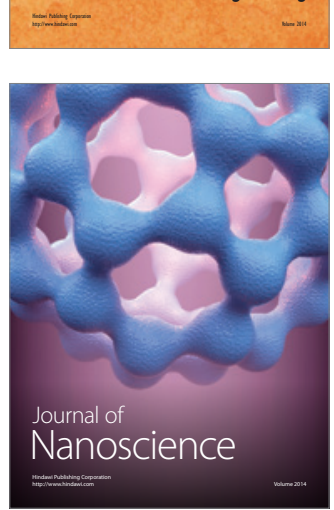
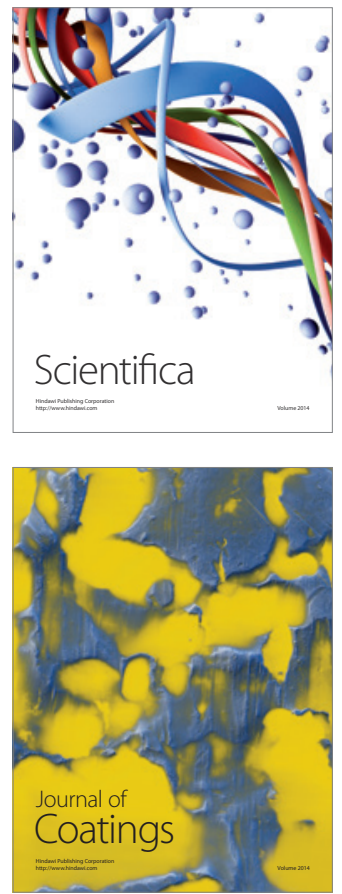
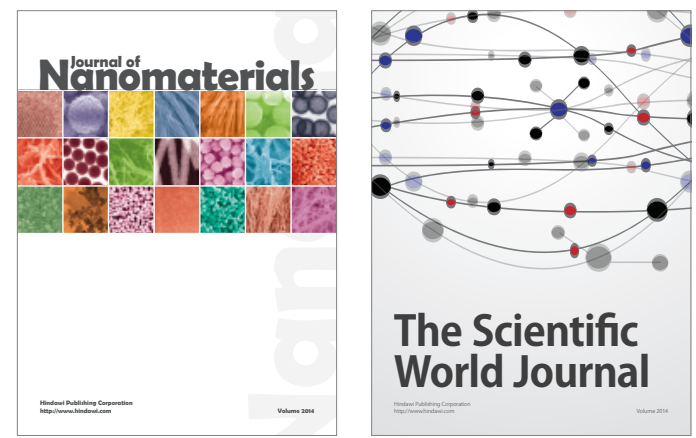

The Scientific World Journal
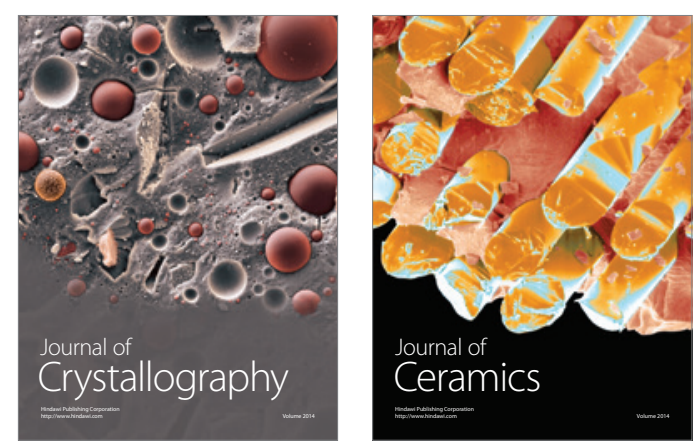
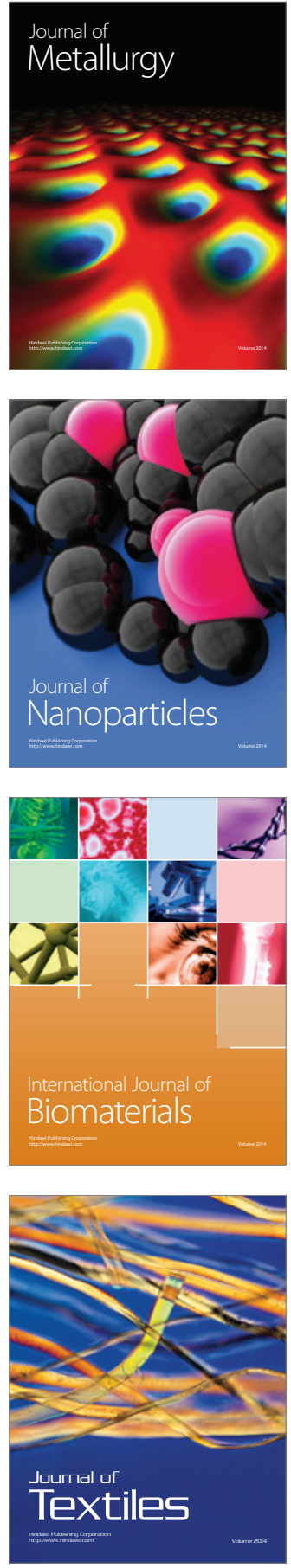